\title{
The subcellular location of cyclin B1 and CDC25 associated with the formation of polyploid giant cancer cells and their clinicopathological significance
}

\author{
Fei Fei ${ }^{1,2} \cdot$ Jie $\mathrm{Qu}^{1,2} \cdot$ Kai $\mathrm{Liu}^{3} \cdot$ Chunyuan $\mathrm{Li}^{1,2} \cdot$ Xinlu Wang ${ }^{2,4} \cdot$ Yuwei $\mathrm{Li}^{5} \cdot$ Shiwu Zhang $\mathbb{\circledR}^{2}$ \\ Received: 6 February 2018 / Revised: 5 September 2018 / Accepted: 4 October 2018 / Published online: 28 November 2018 \\ (c) United States \& Canadian Academy of Pathology 2018
}

\begin{abstract}
Polyploid giant cancer cells (PGCCs) are key contributors to cancer heterogeneity, and the formation of PGCCs is associated with changes in the expression of cell-cycle-related proteins. This study investigated the intracellular localization and expression level of multiple cell-cycle-related proteins in PGCCs derived from BT-549 and HEY cells. In addition, the formation of PGCCs and the clinicopathological significance of cell-cycle-related proteins in human breast and ovarian cancer were examined. The expression levels of cell-cycle-related proteins, including cyclin B1, CDC25B, CDC25C, and other cell cycle phosphoproteins, including Chk2, and Aurora-A kinase, were determined using immunostaining and western blotting both in vitro and in vivo. Migration, invasion, and proliferation in control cells, cyclin B1 knockdown cells and their PGCCs following $\mathrm{CoCl}_{2}$ treatment were compared. In addition, human breast and ovarian cancer samples were collected to determine the correlation of number of PGCCs, expression of cell-cycle-related proteins, and tumor pathologic grade and metastasis. Our results confirm that cyclin B1 was localized in the cytoplasm of PGCCs and in the nuclei of their budding daughter cells. The phosphorylated proteins Chk2 and Aurora-A kinase regulated the expression and subcellular localization of cyclin B1, CDC25B, and CDC25C. The rate of positive cytoplasmic staining of cyclin B1 and positive nuclear staining of both $\mathrm{CDC} 25 \mathrm{~B}$ and $\mathrm{CDC} 25 \mathrm{C}$ increased with increase in tumor grade and lymph node metastasis. Cell-cycle-related proteins, including cyclin $\mathrm{B} 1, \mathrm{CDC} 25 \mathrm{~B}$, and $\mathrm{CDC} 25 \mathrm{C}$ play an important role in regulating the formation of PGCCs. The inhibition of cyclinB1 and $\mathrm{CoCl}_{2}$ treatment significantly promoted cell proliferation, invasion, and migration abilities. The subcellular localization of these cell-cycle-related proteins was regulated by other cell cycle phosphoproteins, and was associated with pathologic grade and metastasis of tumors in cases of human breast and ovarian cancer.
\end{abstract}

These authors contributed equally: Fei Fei, Jie Qu

Electronic supplementary material The online version of this article (https://doi.org/10.1038/s41374-018-0157-x) contains supplementary material, which is available to authorized users.

Shiwu Zhang

zhangshiwu666@aliyun.com

1 Nankai University School of Medicine, Nankai University, Tianjin 300071, China

2 Departments of Pathology, Tianjin Union Medical Center, Tianjin 300121, China

3 Tianjin Medical University, Tianjin 300070, China

4 Graduate School, Tianjin University of Traditional Chinese Medicine, Tianjin, China

5 Departments of Colorectal Surgery, Tianjin Union Medical Center, Tianjin 300121, China

\section{Introduction}

Breast and ovarian cancer are the two most prevalent types of cancer in women, and their incidence is increasing [1,2]. It is universally acknowledged that tumor invasion and metastasis are the main reasons for tumor recurrence and high death rate of cancer patients [3]. Cancer stem cells are a small subset of cancer cells, and are involved in the metastasis, chemoresistance, and recurrence of human cancers. We have previously shown that polyploid giant cancer cells (PGCCs) possess the characteristics of cancer stem cells including asymmetric division and slow-cycle nature, and they can undergo epithelial-mesenchymal transition. The most important feature is the ability of a single PGCC to generate tumors in immunodeficient mice [4-7].

PGCCs are defined as cancer cells with a nucleus at least three times larger than that of a diploid cancer cell. They can be induced in vitro by treating cells with cobalt chloride 
$\left(\mathrm{CoCl}_{2}\right)$. PGCCs are believed to contribute to the promotion of tumor occurrence, development, invasion, metastasis, and chemoresistance [4, 8]. PGCCs are highly resistant to oxygen deprivation and can form through endoreduplication or cell fusion, generate daughter cells, and contribute to the generation of cancer stem-like cells [7]. PGCCs differ from diploid cancer cells in terms of their appearance, size, and tumorigenic ability. The average length of a PGCC is at least three times greater than regular-sized diploid tumor cells. Although the detailed mechanisms underlying the formation of PGCCs have not been completely defined, it has been reported that multiple types of cell-cycle-related proteins, including CDKs, cyclin B1, cyclin E, and cyclin D1 are dysregulated during the formation of PGCCs. Among these cell-cycle proteins, cyclin B1 has been suggested to be the most important with respect to the formation of PGCCs [7, 9, 10].

Cyclin B1 plays an important role during the G2/M phase of the cell cycle. Subcellular localization of cyclin B1 determines its function during the cell cycle, and is regulated by phosphorylation. As a result of its phosphorylation, cyclin B1 is imported into the nucleus [9, 10]. Suzuki et al. have reported that nuclear-dominant expression of cyclin B1 leads to poorer prognosis in breast cancer [11]. Overexpression of cyclin B1 can also lead to uncontrolled cell growth in cancer.

One of the most prominent features of cancer cells is dysregulated growth and uncontrolled proliferation, which can mostly be attributed to cell cycle dysregulation [12]. Among all the cell-cycle-related proteins, cyclin B1 and cell division cycle 25 (CDC25) play important roles in regulating cell cycle progression, as well as participating in the development of a variety of human malignancies. Nuclear expression of cyclin B1 causes transition of the cell from the $\mathrm{G} 2$ to $\mathrm{M}$ phase, whereas cytoplasmic expression of cyclin B1 can cause G2/M arrest. A high level of expression of cyclin B1 in the cytoplasm has been shown to be associated with the formation of PGCCs. PGCCs are produced through a process referred to as endoreduplication (i.e., replication of the nuclear genome in the absence of mitosis) or through cell fusion, and the daughter cells are formed through asymmetric cell division [4, 13, 14]. Due to the polyploid genome and increased cell size, multinucleated giant cells are formed as a result of an abnormal cell cycle, including continued DNA replication and aberrant cell division [13, 15-19]. Therefore, G2/M transition-related proteins, including cyclin $\mathrm{B} 1$ and $\mathrm{CDC} 25$, were taken into consideration during the investigation of the molecular mechanisms underlying the formation of PGCCs.

In this study, $\mathrm{CoCl}_{2}$ was used as a hypoxia-mimic to induce the formation of PGCCs in BT-549 and HEY cancer cells. We have previously reported that hypoxia is associated with alterations in the expression of $\mathrm{G} 2 / \mathrm{M}$ checkpoint regulators, including cyclin $\mathrm{B} 1$ and $\mathrm{CDC} 25$, and there are more PGCCs in $\mathrm{G} 2 / \mathrm{M}$ phase after $\mathrm{CoCl}_{2}$ treatment [7]. The effects of hypoxia on $\mathrm{G} 2 / \mathrm{M}$ transition regulators includes alterations in their expression levels, and it also influences their subcellular localization, which may be involved in the formation of PGCCs. The aim of this study was to compare the intracellular localization and expression level of cyclin B1 and CDC25 among control cells, cyclin B1i cells, and PGCCs, and to explore the mechanisms of PGCC formation. Additionally, this study aimed to demonstrate the clinicopathological significance of cyclin B1 and CDC25 subcellular expression in human breast cancer and human ovarian cancer.

\section{Materials and Methods}

\section{Cancer cell lines and culture}

The human breast cancer cell line BT-549 and the human ovarian cancer cell line HEY were obtained from the American Type Culture Collection, Manassas, VA. Cells were maintained in RPMI-1640 medium that was supplemented with $10 \%$ fetal bovine serum (FBS), $100 \mathrm{U} / \mathrm{mL}$ penicillin, and $100 \mu \mathrm{g} / \mathrm{mL}$ streptomycin. Cells were incubated at $37^{\circ} \mathrm{C}$ and $5 \% \mathrm{CO}_{2}$ under moderate humidity.

\section{Formation of PGCCs}

The formation of PGCCs was carried out as described previously [7]. The detailed methods are provided in the Supplementary Materials and Methods. After 3-4 rounds of $\mathrm{CoCl}_{2}$ treatment, the PGCCs and their daughter cells were used for immunocytochemical (ICC) staining, western blotting and other analyses.

\section{Inhibition of the expression of cyclin B1 in BT-549 and HEY cells}

BT-549 and HEY cells were maintained in RPMI-1640 medium. When the confluency of the BT-549 and HEY cells reached $\sim 60 \%$, the cells were infected with a retrovirus containing pBabe-puro-cyclin B1 siRNA targeting cyclin B1 mRNA, as described previously [7]. Puromycin $(2 \mu \mathrm{g} /$ $\mathrm{mL}$ ) was used to select the cells with a stable knockdown of cyclin B1 expression (cyclin B1i).

\section{Hematoxylin and eosin (H\&E) staining}

H\&E staining was carried out as described previously [5]. The detailed information is provided in the Supplementary Materials and Methods. 
ICC staining assays and immunohistochemical (IHC) staining

ICC and IHC staining using an avidin-biotin-peroxidase complex were performed as previously described [20]. Detailed information, including the primary antibodies used, is provided in the Supplementary Materials and Methods.

\section{Preparation of total protein and separation of nuclear and cytoplasmic proteins}

Nuclear and cytoplasmic protein fractions were prepared using an extraction kit (Beyotime Biotechnology, Shanghai, China) according to the manufacturer's instructions [21-23]. Total protein extraction was performed by lysis in ice cold buffer for $30 \mathrm{~min}$, as described previously [6, 7].

\section{Western blot analysis}

Western blot analysis was performed as previously described [4, 7]. Information on the primary antibodies and reagents is provided in the Supplementary Materials and Methods.

\section{Cell migration assay}

Wound-scratch assay was performed to evaluate the migration abilities of control cells, cyclin B1i cells, and their PGCCs with budding daughter cells of BT-549 and $\mathrm{HEY}$ after $\mathrm{CoCl}_{2}$ treatment. Cells were plated on six-well plates, and wound tracks were created by scraping the cell monolayer with sterile pipette tips after culturing at $37^{\circ} \mathrm{C}$ with $5 \% \mathrm{CO}_{2}$. Detached cells were removed by washing with PBS and were subsequently incubated in complete medium. The ability of cells to migrate to the wound areas was assessed by comparing the wound tracks in the images taken after $0,6,9,12,18,24,30$, and $42 \mathrm{~h}$. Using Image-J software, the migration index was calculated using the following formula: [(wound area at $0 \mathrm{~h})-$ (wound area at indicated time point)] / (wound area at $0 \mathrm{~h}$ ). A higher score indicates better migration ability.

Migration ability was also measured via transwell migration assay using cell culture inserts $(8 \mu \mathrm{m}$; Corning Inc., Corning, NY) in a 24 -well plate. Cells $\left(5 \times 10^{4}\right.$ cells per insert) in $200 \mu \mathrm{L}$ medium without FBS were added to the upper chamber. At the same time, culture medium containing 20\% FBS was added to the lower chamber, after which the plates were incubated for $12 \mathrm{~h}$ (for HEY) to $24 \mathrm{~h}$ (for BT-549) at $37^{\circ} \mathrm{C}$. After removing the medium without FBS and the upper chamber, transwell inserts and migrated cells were fixed in methanol for $30 \mathrm{~min}$ and stained with $0.1 \%$ crystal violet for $30 \mathrm{~min}$. Migration ability was assessed by counting the number of cells per field. Photos were taken at $100 \times$ magnification, and cells were counted from at least 5 different fields. Three independent experiments were performed.

\section{Cell invasion assay}

For the transwell invasion assay, cell suspensions were prepared at $5 \times 10^{5}$ cells per well and subsequently seeded in $100 \mu \mathrm{L}$ medium without FBS onto inserts precoated with BD Matrigel Basement Membrane Matrix (Corning). Growth medium, with $20 \%$ FBS as the chemoattractant, was added to the bottom chamber, and plates were incubated for $12 \mathrm{~h}$ (for HEY) to $24 \mathrm{~h}$ (for BT-549) at $37^{\circ} \mathrm{C}$. After removing the medium without FBS and the upper chamber, the transwell inserts and invasive cells were fixed in methanol for $30 \mathrm{~min}$ and then stained using $0.1 \%$ crystal violet for $30 \mathrm{~min}$. The invasion ability of cells was assessed by counting the number of invasive cells per field. Three independent experiments were performed.

\section{Cell proliferation assay}

The absorbance of control cells, cyclin B1i cells, and their PGCCs with budding daughter cells for both BT-549 and HEY cells were measured using the Cell Counting Kit-8 (CCK-8; Dojindo Molecular Technologies, Inc., Shanghai, China) according to the manufacturer's instructions. Cells were seeded on a 96-well plate at an appropriate density $\left(1 \times 10^{4}\right.$ or $2 \times 10^{4}$ cells per well $)$ in $100 \mu \mathrm{L}$ culture medium. Cells were cultured in an incubator at $37^{\circ} \mathrm{C}$ for 24 or $48 \mathrm{~h}$. CCK-8 solution was added to each well, and the plate was incubated for 1 to $3 \mathrm{~h}$. The absorbance at $450 \mathrm{~nm}$ was measured using a microplate reader.

\section{Animal experiments}

Control cells or PGCCs (from either HEY or BT-549 cells) at densities of $1 \times 10^{5}$ cells were subcutaneously injected into the flanks of 6- to 8 -week-old nude mice ( 5 mice per group). One month later, the mice were killed by cervical dislocation following $\mathrm{CO}_{2}$ inhalation, and the tumors were removed and fixed in $10 \%$ formalin for routine histological examination and immunohistochemical staining. To assess the number of cyclin B1-positive cells in tumor tissue, 5 microscopic fields in each tissue section were evaluated at $\times 400$ magnification, using microscopic fields filled with mostly tumor cells. Results are expressed as the average number of cyclin B1-positive cells per high-power field. Procedures for the care and use of mice were approved by the Animal Care and Use Committee of the Tianjin Union Medical Center, Tianjin, China. 


\section{Tissue samples}

Paraffin-embedded human breast cancer tissue samples ( $n$ $=188$, average age $=58.16 \pm 11.08$ ) and human ovarian cancer tissue samples $(n=67$, average age $=55.69 \pm 12.71)$ were obtained from the Department of Pathology of the Tianjin Union Medical Center. None of the patients had been treated before complete surgical removal of the tumor. Pathologically, the 188 cases of breast cancer were divided into 2 groups: 54 cases of lymph node metastatic breast cancer (group 1), and 134 cases of primary invasive breast cancer (group 2). Similarly, the 67 cases of ovarian cancer were classified into 4 groups: 15 cases of primary serous ovarian cancer with lymph node metastasis (group I), and their corresponding lymph node metastatic tumor (group II); 29 cases of primary serous ovarian cancer without metastasis (group III); and 8 cases of serous borderline cystadenoma (group IV). The Hospital Review Board of the Tianjin Union Medical Center approved this study and the confidentiality of patient information was maintained.

\section{Tissue microarray}

Tissue microarrays were assembled as previously described [24]. Detailed information is provided in the Supplementary Materials and Methods.

\section{PGCC definition and counting}

Based on our previous methods [2, 5, 7], PGCCs were characterized as a subpopulation of tumor cells having a nucleus at least 3 times larger than that of regular diploid tumor cells. Five microscopic fields in each tissue section were viewed under $\times 400$ magnification and the average number of cells was calculated. The size of each PGCC nuclei was measured using a micrometer.

\section{Scoring of immunostained tissue sections}

In order to quantify protein expression, both the intensity and percentage of positive cells were evaluated, based on the methods described by $\mathrm{Lv}$ et al.[2, 25]. The detailed information is shown in the Supplementary Materials and Methods.

\section{Statistical analysis}

All the data were processed using SPSS 17.0 statistical software (IBM Corporation, Armonk, NY). Kruskal-Wallis test was performed to compare differences in the number of PGCCs and the expression level of cell-cycle-related proteins among the 4 groups of ovarian cancer. Mann-Whitney $\mathrm{U}$ test was used to analyze differences in the number of
PGCCs as well as the expression level of cell-cycle-related proteins between breast cancer groups. Other comparisons were performed with two-tailed Student's $t$ test and Pearson' s chi-square $\left(\chi^{2}\right)$ test. $P<0.05$ was used for statistical significance.

\section{Results}

\section{Formation of PGCCs following $\mathrm{CoCl}_{2}$ treatment, and number of PGCCs associated with cyclin B1i}

Sporadic PGCCs were observed in BT-549 and HEY cell lines grown in RPMI-1640 medium (Fig. 1A-a, B-a). When $\mathrm{CoCl}_{2}$ was added to the medium, regular-sized cells were selectively killed, whereas PGCCs survived the $\mathrm{CoCl}_{2}$ treatment (Fig. 1A, b, B, b). Compared with the parental control BT-549 and HEY cells, cyclin B1i cells were slightly irregular in shape and more PGCCs were observed. Cyclin B1i cells showed an increased resistance to $\mathrm{CoCl}_{2}$ treatment. When treated with $450 \mu \mathrm{M} \mathrm{CoCl}_{2}$ for $48 \mathrm{~h}$ (BT549 cyclin B1i cells) or $450 \mu \mathrm{M} \mathrm{CoCl}_{2}$ for $72 \mathrm{~h}$ (HEY cyclin B1i cells), more PGCCs survived compared to the corresponding parental control cells, which expressed normal levels of cyclin B1 (Fig. 1A-c, B, c). When treated with the same concentration of $\mathrm{CoCl}_{2}$, there were more surviving PGCCs in the cyclin B1i cells compared with the corresponding parental control cells (Fig. 1A-d, B-d).

To further explore whether cyclin B1 knockdown affects the formation of PGCCs, H\&E staining was performed on the parental control cells (BT-549 and HEY), cyclin B1i cells, and their corresponding cells after $\mathrm{CoCl}_{2}$ treatment (For convenience, the latter 2 groups were named PGCCs and cyclin B1i PGCCs) (Fig. 1C, D). PGCCs in the different groups were then counted. The data in Table 1 show that there were higher numbers of PGCCs in the cyclin B1i cells than in both of their respective parental control cells (BT-549 and HEY). This difference was statistically significant $(P=0.000)$. Similarly, the cyclin B1i cells treated with $\mathrm{CoCl}_{2}$ produced markedly more PGCCs than the corresponding parental control cells that were treated with the same concentration of $\mathrm{CoCl}_{2}$ for the same duration of time (Fig. 1E, F). Taken together, these data suggest that the knockdown of cyclin B1 increases the number of PGCCs.

\section{Intracellular localization and expression levels of Chk1, Chk2, PLK1, CDC25B, CDC25C, Aurora A, and cyclin B1}

The parental BT-549 or HEY control cells, the cyclin B1i cells, and their corresponding cells after $\mathrm{CoCl}_{2}$ treatment, were cultured on coverslips for ICC staining (Fig. 2A a-d, A $\mathrm{e}-\mathrm{h})$. Cyclin B1 ICC staining showed that the highest 

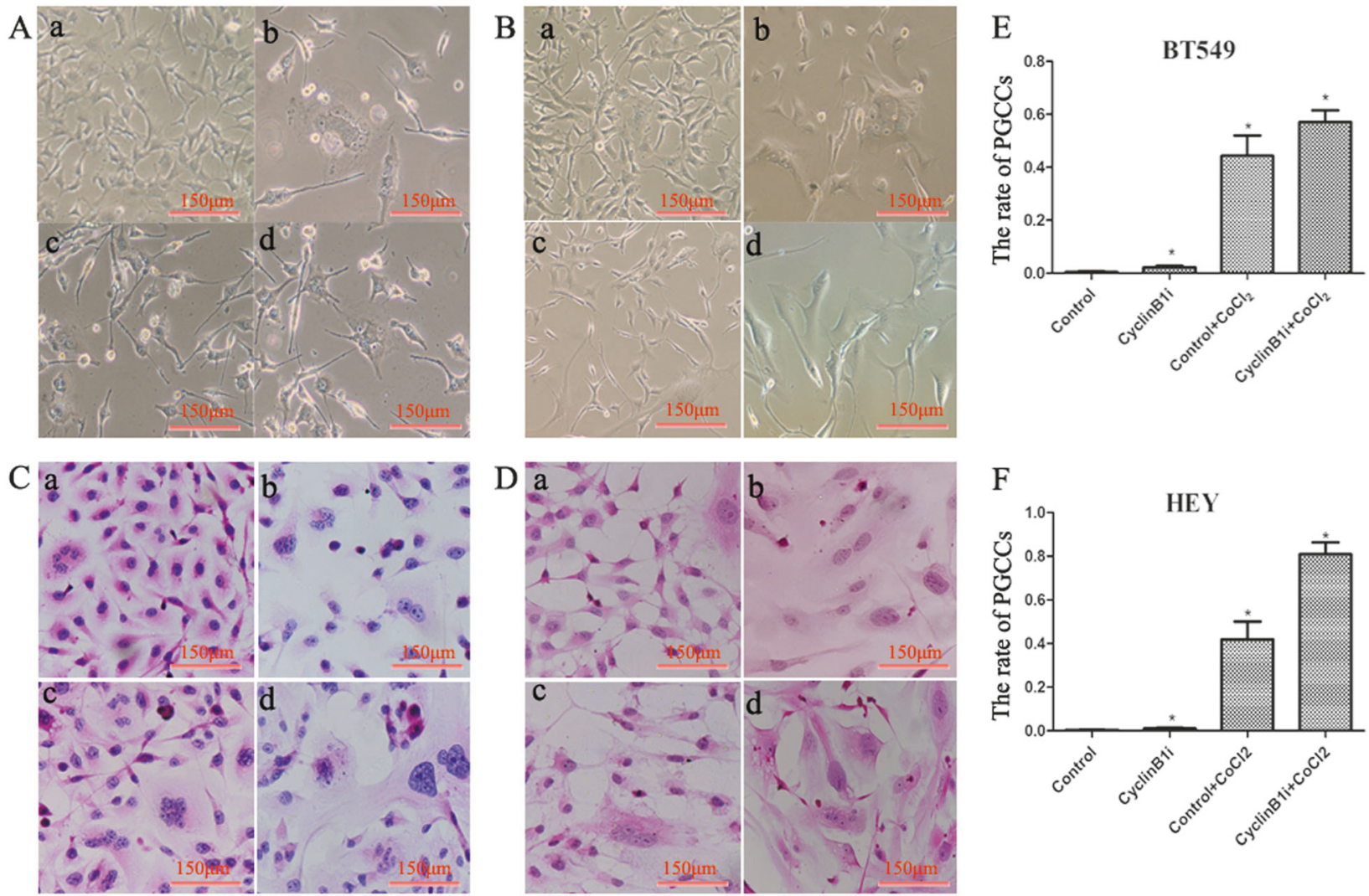

Fig. 1 A Morphologic characteristics of BT-549 cells. (a) Morphologic characteristics of parental BT-549 cells cultured in complete RPMI1640 (10x). (b) BT-549 PGCCs that survived treatment with $450 \mu \mathrm{M}$ $\mathrm{CoCl}_{2}$ for $24 \mathrm{~h}(10 \mathrm{x})$. (c) Morphologic characteristics of cyclin B1i BT-549 cells. (d) Cyclin B1i BT-549 PGCCs that survived treatment with $450 \mu \mathrm{M} \mathrm{CoCl}$ for $24 \mathrm{~h}(10 \times)$. B Morphologic characteristics of HEY cells. (a) Morphologic characteristics of parental HEY cells cultured in complete RPMI-1640 (10x). (b) HEY PGCCs that survived treatment with $450 \mu \mathrm{M} \mathrm{CoCl} 2$ for $48 \mathrm{~h}(10 \times)$. (c) Morphologic characteristics of cyclin B1i HEY cells. (d) Cyclin B1i HEY PGCCs that survived treatment with $450 \mu \mathrm{M} \mathrm{CoCl}_{2}$ for $48 \mathrm{~h}(10 \times)$. C H\&E

staining of BT-549 cells. (a) H\&E staining of parental BT-549 cells $(10 \times)$. (b) H\&E staining of BT-549 PGCCs $(10 \times)$. (c) H\&E staining of cyclin B1i BT-549 cells (10x). (d) H\&E staining of cyclin B1i BT549 PGCCs $(10 \times)$. D H\&E staining of HEY cells $(10 \times)$. (a) H\&E staining of parental HEY cells $(10 \times)$. (b) H\&E staining of HEY PGCCs $(10 \times)$. (c) H\&E staining of cyclin B1i HEY cells $(10 \times)$. (d) $\mathrm{H} \& \mathrm{E}$ staining of cyclin B1i HEY PGCCs $(10 \times)$. $\mathbf{E}$ Rate of PGCCs in the different groups of BT-549 cells. F Rate of PGCCs in the different groups of HEY cells. All the data represent the mean \pm SD of 3 independent experiments

Table 1 Rate of PGCCs in different groups of BT-549 and HEY cells

\begin{tabular}{llllllll}
\hline BT-549 & Rate of PGCCs & $t$ & $P$ value & HEY & Rate of PGCCs & $t$ \\
\hline Control & $0.0035 \pm 0.0024$ & & & Control & $0.0018 \pm 0.0016$ & $P$ value \\
Cyclin B1i & $0.0216 \pm 0.0062$ & $-6.062^{\mathrm{a}}$ & $0.000^{\mathrm{a}}$ & Cyclin B1i & $0.0105 \pm 0.0029$ & $-5.718^{\mathrm{a}}$ & $0.000^{\mathrm{a}}$ \\
PGCCs & $0.4438 \pm 0.0763$ & $-12.892^{\mathrm{a}}$ & $0.000^{\mathrm{a}}$ & PGCCs $^{\mathrm{a}}$ & $0.4183 \pm 0.0825$ & $-11.286^{\mathrm{a}}$ & $0.000^{\mathrm{a}}$ \\
Cyclin B1i PGCCs & $0.5707 \pm 0.0444$ & $-3.213^{\mathrm{b}}$ & $0.012^{\mathrm{b}}$ & Cyclin B1i PGCCs & $0.8087 \pm 0.0539$ & $8.859^{\mathrm{b}}$ & $0.000^{\mathrm{b}}$ \\
\hline
\end{tabular}

${ }^{\mathrm{a} C}$ Comparison of treatment groups vs. control group $(t$ test)

${ }^{\mathrm{b}}$ Comparison of cyclin B1i PGCCs group vs. PGCCs group ( $t$ test)

number of cyclin B1-positive cells were present in the parental control cells, and the least number of cyclin B1-positive cells was in cyclin B1i cells after $\mathrm{CoCl}_{2}$ treatment (Fig. 2B $\mathrm{a}, \mathrm{b})$. The total number of cyclin B1-positive cells (including nucleus-positive and cytoplasm-positive) in both cyclin B1i cells and cells after $\mathrm{CoCl}_{2}$ treatment were less than that of the parental cells before $\mathrm{CoCl}_{2}$ treatment (Table 2).
Positive cyclin B1 staining was found in the nucleus of diploid cancer cells and in the cytoplasm of PGCCs. It is believed that translocation of cyclin B1 into the nucleus plays an essential role in regulating the onset of mitotic events in cells. However, the failure of nuclear translocation in PGCCs may prevent the initiation of mitotic events after DNA replication has been completed and leads to the 

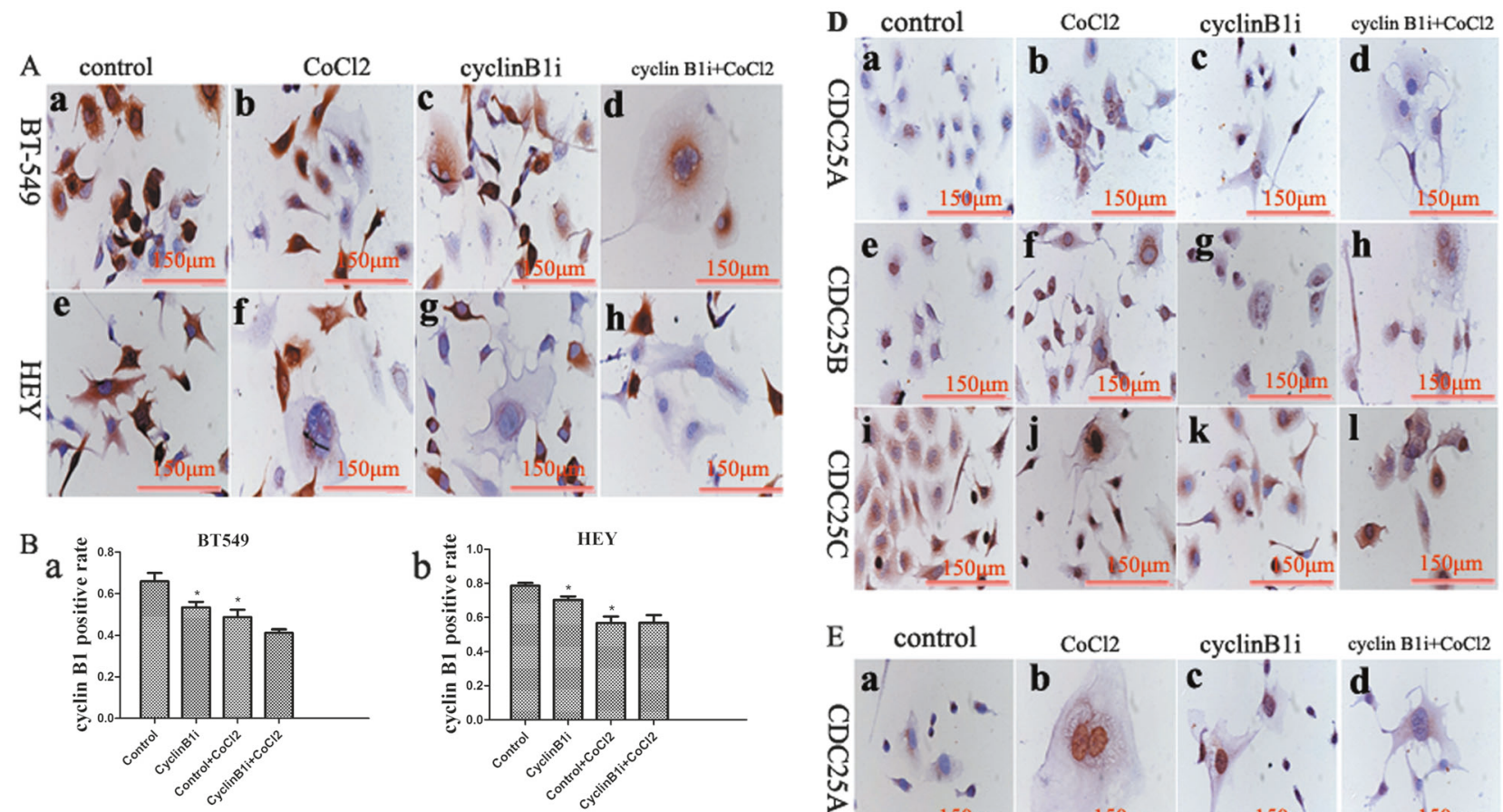

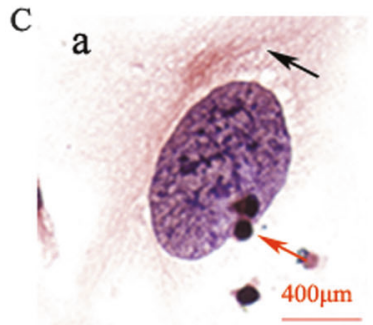

BT-549

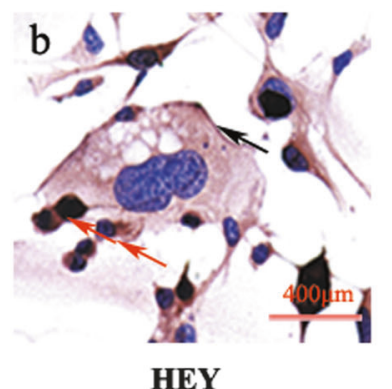

HEY
Fig. 2 A ICC staining of BT-549 and HEY cells (ICC, 10x). (a-d) ICC staining of cyclin B1 in BT-549 cells (a) parental control cells, (b) control cells after $\mathrm{CoCl}_{2}$ treatment, (c) cyclin B1i cells, and (d) cyclin B1i cells after $\mathrm{CoCl}_{2}$ treatment. (e-h) ICC staining of cyclin B1 in HEY cells (e) parental control cells, (f) control cells after $\mathrm{CoCl}_{2}$ treatment, (g) cyclin B1i cells, and (h) cyclin B1i cells after $\mathrm{CoCl}_{2}$ treatment. B (a) Bar graph showing the average cyclin B1-positivity rate in the different groups of BT-549 cells. (b) Bar graph showing the average cyclin B1-positivity rate in the different groups of HEY cells. C. Cyclin B1 ICC staining of BT-549 and HEY cells. (a) Cyclin B1 located in the nuclei of daughter cells (red arrow points) and the cytoplasm of PGCCs (black arrow points) from BT-549 cells (ICC, 40×). (b) Cyclin B1 located in the nuclei of daughter cells (red arrow points) and the cytoplasm of PGCCs (black arrow points) from HEY cells (ICC, 40x). D ICC staining of BT-549 cells $($ ICC, $10 \times)$ ). (a-d) ICC staining of CDC25A in (a) parental control

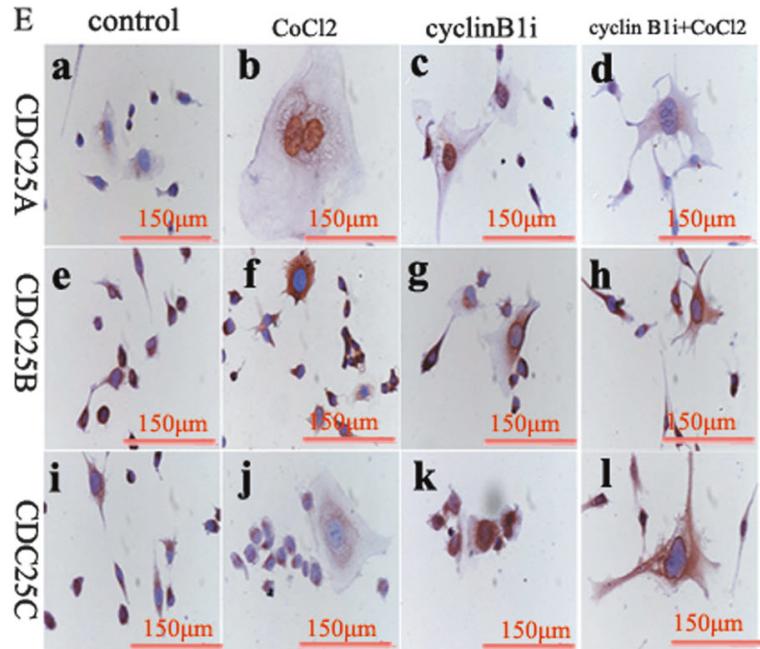

cells, (b) control cells after $\mathrm{CoCl}_{2}$ treatment, (c) cyclin B1i cells, and (d) cyclin B1i cells after $\mathrm{CoCl}_{2}$ treatment. (e-h) ICC staining of CDC25B in (e) parental control cells, (f) control cells after $\mathrm{CoCl}_{2}$ treatment, (g) cyclin B1i cells, and (h) cyclin B1i cells after $\mathrm{CoCl}_{2}$ treatment. (i-l) ICC staining of $\mathrm{CDC} 25 \mathrm{C}$ in (i) parental control cells, (j) control cells after $\mathrm{CoCl}_{2}$ treatment, (k) cyclin B1i cells, and (l) cyclin B1i cells after $\mathrm{CoCl}_{2}$ treatment. E ICC staining of HEY cells (ICC, 10×). (a-d) ICC staining of CDC25A in (a) parental control cells, (b) control cells after $\mathrm{CoCl}_{2}$ treatment, (c) cyclin B1i cells, and (d) cyclin B1i cells after $\mathrm{CoCl}_{2}$ treatment. (e-h) ICC staining of CDC25B in (e) parental control cells, (f) control cells after $\mathrm{CoCl}_{2}$ treatment, (g) cyclin B1i cells, and (h) cyclin B1i cells after $\mathrm{CoCl}_{2}$ treatment. (i-l) ICC staining of $\mathrm{CDC} 25 \mathrm{C}$ in (i) parental control cells, (j) control cells after $\mathrm{CoCl}_{2}$ treatment, (k) cyclin $\mathrm{B} 1 \mathrm{i}$ cells, and (l) cyclin B1i cells after $\mathrm{CoCl}_{2}$ treatment

positive staining was located in both the cytoplasm and nucleus (Fig. 2D-b, E-b). The expression of CDC25A decreased after cyclin B1 knockdown (Fig. 2D-c, d, E-c, d). The expression of both CDC25B (Fig. 2D e-h, E e-h) and CDC25C (Fig. 2D i-1, E i-1) in BT-549 and HEY were mainly focused in the cytoplasm in PGCCs with budding daughter cells after $\mathrm{CoCl}_{2}$ treatment. The cytoplasmic expression of $\mathrm{CDC} 25 \mathrm{~B}$ and $\mathrm{CDC} 25 \mathrm{C}$ in PGCCs was 
Table 2 The average rate of cyclin B1-positive cells in different groups of BT-549 and HEY

\begin{tabular}{llllllll}
\hline BT-549 & $\begin{array}{l}\text { Average cyclin } \\
\text { B1-positivity rate }\end{array}$ & $t$ & $P$ value & HEY & $\begin{array}{l}\text { Average cyclin } \\
\text { B1-positivity rate }\end{array}$ & $t$ & $P$ value \\
\hline Control & $0.6599 \pm 0.0885$ & & & Control & $0.7855 \pm 0.0366$ & & \\
Cyclin B1i & $0.5335 \pm 0.5935$ & $2.652^{\mathrm{a}}$ & $0.029^{\mathrm{a}}$ & Cyclin B1i & $0.7019 \pm 0.0468$ & $3.145^{\mathrm{a}}$ & $0.014^{\mathrm{a}}$ \\
PGCCs & $0.4863 \pm 0.0804$ & $3.245^{\mathrm{a}}$ & $0.012^{\mathrm{a}}$ & PGCCs & $0.5662 \pm 0.0865$ & $5.217^{\mathrm{a}}$ & $0.001^{\mathrm{a}}$ \\
Cyclin B1i & $0.4123 \pm 0.0363$ & $1.876^{\mathrm{b}}$ & $0.098^{\mathrm{b}}$ & Cyclin B1i & $0.5675 \pm 0.1011$ & $-0.022^{\mathrm{b}}$ & $0.983^{\mathrm{b}}$ \\
PGCCs & & & & PGCCs & & & \\
\hline
\end{tabular}

${ }^{\mathrm{a} C}$ Comparison of treatment groups vs. control group $(t$ test $)$

${ }^{\mathrm{b}}$ Comparison of cyclin B1i PGCCs group vs. PGCCs group $(t$ test $)$ associated with failure of G2/M transition and cell division, resulting in the formation of PGCCs.

Using ICC staining, some PGCCs were found to be negative for cyclin B1, whereas other PGCCs were positive. In some PGCCs, both the cytoplasm and nucleus were found to be positive for cyclin B1 staining, whereas in other PGCCs cyclin B1 was only found in the cytoplasm (Fig. 2A $\mathrm{a}-\mathrm{d}$, a e-h). To quantify the subcellular localization of cyclin B1 in PGCCs, PGCCs positively stained for cyclin $\mathrm{B} 1$ were counted and analyzed. The relative number of cyclin B1-positive PGCCs present were lowest in the parental control cells, increased in the cyclin B1i cells, PGCCs after $\mathrm{CoCl}_{2}$ treatment, and highest in cyclin B1i PGCCs after $\mathrm{CoCl}_{2}$ treatment. The number of cyclin B1-positive cells showing staining in the cytoplasm of PGCCs showed the same trend and increased accordingly (Fig. 3Aa, b).

Western blotting of total protein showed that, compared to control cells, the expression levels of CDC25B, $\mathrm{CDC} 25 \mathrm{C}$, and cyclin $\mathrm{B} 1$ in PGCCs were lower after $\mathrm{CoCl}_{2}$ treatment, and the expression levels of Chk2 and Aurora A in HEY and BT-549 cells were lower after $\mathrm{CoCl}_{2}$ treatment (Fig. 3B). Western blotting of subcellular fractions after separation of cytoplasmic and nuclear proteins suggested that Chk1, Chk2, PLK1, CDC25B, CDC25C, Aurora A, and cyclin B1 were mainly observed in the cytoplasm of HEY and BT-549 cells. The expression levels of Chk1, Chk2, CDC25B, CDC25C, and cyclin B1 in HEY PGCCs after $\mathrm{CoCl}_{2}$ treatment were lower than those of control cells. There were no differences in PLK1 and Aurora A expression before and after $\mathrm{CoCl}_{2}$ treatment (Fig. 3C). The expression level of CDC25C in BT-549 after $\mathrm{CoCl}_{2}$ treatment was lower than that of control cells. The expression levels of Chk1, Chk2, Aurora A, and cyclin B1 increased after $\mathrm{CoCl}_{2}$ treatment (Fig. 3D.

Results of Aurora A, PLK1, Chk1, and Chk2 ICC staining were consistent with the results of western blotting. In HEY control cells, both the cytoplasm and nuclei were positive for Aurora A, PLK1, and Chk2 ICC staining. In BT-549 control cells, positive Aurora A, PLK1, Chk1 and Chk2 ICC staining was mainly located in the cytoplasm. In HEY and BT-549 cells after $\mathrm{CoCl}_{2}$ treatment, the expression of Aurora A, PLK1, Chk1, and Chk2 was restricted to the cytoplasm of PGCCs (Fig. 3E, F).

\section{Comparison of migration, invasion, and proliferation abilities of control cells, cyclin B1i cells, and their PGCCs after $\mathrm{CoCl}_{2}$ treatment}

Different cell lines have different migration, invasion, and proliferation abilities. Furthermore, PGCCs acquire cancer stem cell properties after $\mathrm{CoCl}_{2}$ treatment, as well as reduced adherent growth [4, 7]. However, the treatment periods and cell densities used for comparing control vs. cyclin B1i cells and PGCCs vs. cyclin B1i PGCCs using BT-549 and HEY cells were kept constant for all experiments.

To determine whether cyclin $\mathrm{B} 1 \mathrm{i}$ and $\mathrm{CoCl}_{2}$ treatment affects cell migration in BT-549 and HEY cells, a wound healing assay was performed using control cells, cyclin B1i cells, and their PGCCs with budding daughter cells. Figures $4 \mathrm{~A}, \mathrm{~B}$ depict the results of the wound-scratch assay at varying incubation periods. The spaces covering the scratched surface in the panels were observed to gradually become narrower with longer incubation periods (Supplementary Figures 1A, B, C, and D). The cell migration abilities of cyclin B1i cells and cyclin B1i PGCCs were found to increase in both BT-549 (Supplementary Table 1; $t=-16.765, P=0.000$ for cyclin B1i and $t=-199.294, P$ $=0.000$ for $\mathrm{CoCl}_{2}$ ) and HEY cells (Supplementary Table 2; $t=-22.523, P=0.000$ for cyclin B1i and $t=-30.776, P$ $=0.001$ for $\mathrm{CoCl}_{2}$ ) (Fig. 4A, B). Moreover, results of the transwell migration assay showed that the number of migrated cells were higher for cyclin B1i cells and cyclin B1i PGCCs than control cells and PGCCs, respectively, for both BT-549 (Supplementary Table 3; $t=-72.331, P=$ 0.000 for cyclin $\mathrm{B} 1 \mathrm{i}$ and $t=-1.026, P=0.363$ for $\mathrm{CoCl}_{2}$ ) and HEY cells (Fig. 4C, Supplementary Table 4; $t=$ $-58.758, P=0.000$ for cyclin B1i and $t=-40.697, P=$ 0.000 for $\mathrm{CoCl}_{2}$ ) (Supplementary Figure 1E a-d).

To examine whether treatment with cyclin $\mathrm{B} 1 \mathrm{i}$ and $\mathrm{CoCl}_{2}$ affects cell invasion in BT-549 and HEY cells, we performed cell invasion assay using Matrigel-coated 

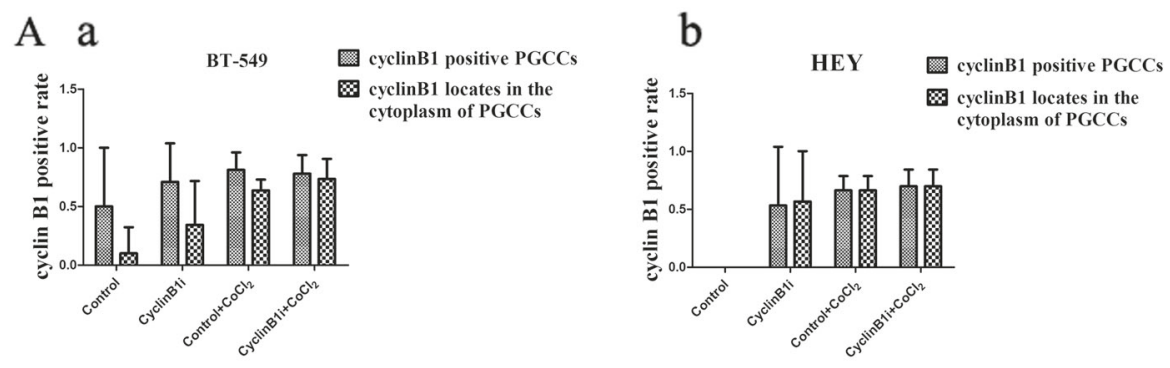

B

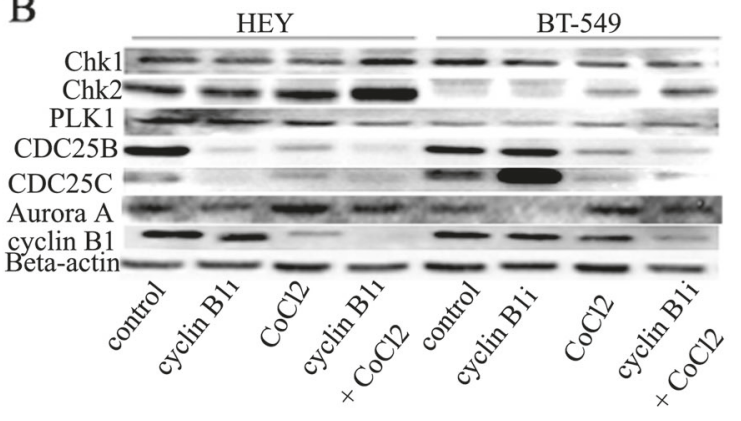

$\mathrm{C}$

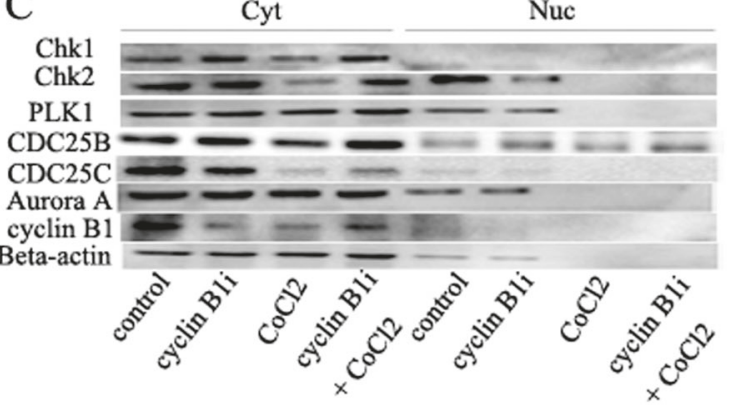

D

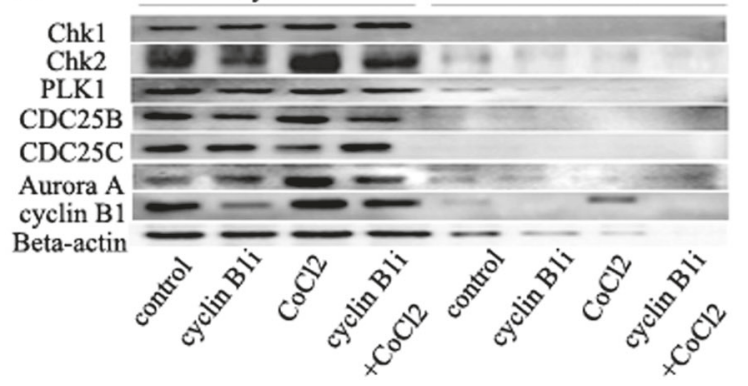

Fig. 3 A (a) BT-549 cells. Bar graphs showing the number of PGCCs positive for cyclin $\mathrm{B} 1$ and cytoplasmic cyclin $\mathrm{B} 1$ in the parental control cells, cyclin B1i cells, PGCCs after $\mathrm{CoCl}_{2}$ treatment, and cyclin $\mathrm{B} 1 \mathrm{i}$ PGCCs after $\mathrm{CoCl}_{2}$ treatment. (b) $\mathrm{HEY}$ cells. Bar graphs showing the number of PGCCs positive for cyclin B1 and cytoplasmic cyclin B1 in the parental control cells, cyclin B1i cells, PGCCs after $\mathrm{CoCl}_{2}$ treatment, and cyclin B1i PGCCs after $\mathrm{CoCl}_{2}$ treatment. B Western blot showing the expression of cyclin $\mathrm{B} 1, \mathrm{CDC} 25 \mathrm{~B}, \mathrm{CDC} 25 \mathrm{C}$, and chk2 in the parental control cells, cyclin $\mathrm{B} 1 \mathrm{i}$ cells, control cells after $\mathrm{CoCl}_{2}$ treatment, and cyclin Bli cells after $\mathrm{CoCl}_{2}$ treatment for both BT-549 and HEY cells. C Nuclear and cytoplasmic expression of cyclin B1, CDC25B, and CDC25C in the parental control HEY cells, cyclin B1i cells, PGCCs after $\mathrm{CoCl}_{2}$ treatment, and cyclin B1i PGCCs after $\mathrm{CoCl}_{2}$ treatment. D Nuclear and cytoplasmic expression of cyclin $\mathrm{B} 1, \mathrm{CDC} 25 \mathrm{~B}$, and $\mathrm{CDC} 25 \mathrm{C}$ in the parental control BT-549 cells, cyclin Bli cells, PGCCs after $\mathrm{CoCl}_{2}$ treatment, and cyclin B1i PGCCs after $\mathrm{CoCl}_{2}$ treatment. E ICC staining of Aurora-A kinase, PLK1, Chk1, and Chk2 in HEY cells (ICC, 10×). (a-d) ICC staining of Aurora-A kinase. (a) control cells, (b) cyclin B1i SPRINGER NATURE
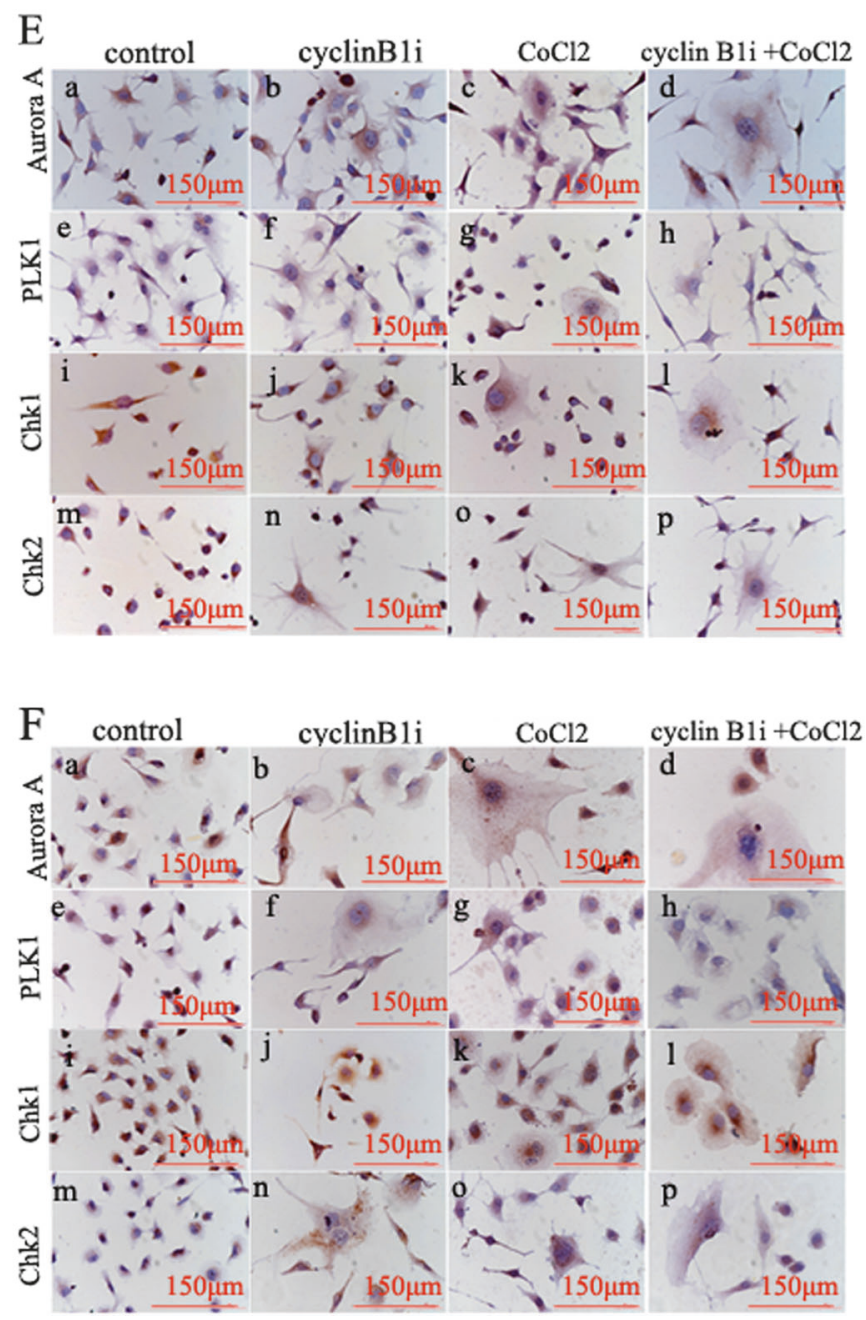

cells, (c) control cells after $\mathrm{CoCl}_{2}$ treatment, and (d) cyclin B1i cells after $\mathrm{CoCl}_{2}$ treatment. (e-h) ICC staining of PLK1. (a) control cells, (b) cyclin B1i cells, (c) control cells after $\mathrm{CoCl}_{2}$ treatment, and (d) cyclin B1i cells after $\mathrm{CoCl}_{2}$ treatment. (i-1) ICC staining of Chk1. (a) control cells, (b) cyclin B1i cells, (c) control cells after $\mathrm{CoCl}_{2}$ treatment, and (d) cyclin B1i cells after $\mathrm{CoCl}_{2}$ treatment. (m-p) ICC staining of Chk2. (a) control cells, (b) cyclin B1i cells, (c) control cells after $\mathrm{CoCl}_{2}$ treatment, and (d) cyclin B1i cells after $\mathrm{CoCl}_{2}$ treatment. F ICC staining of Aurora-A kinase, PLK1, Chk1, and Chk2 in BT-549 cells (ICC, 10x). (a-d) ICC staining of Aurora-A kinase. (a) control cells, (b) cyclin B1i cells, (c) control cells after $\mathrm{CoCl}_{2}$ treatment, and (d) cyclin B1i cells after $\mathrm{CoCl}_{2}$ treatment. (e-h) ICC staining of PLK1. (a) control cells, (b) cyclin B1i cells, (c) control cells after $\mathrm{CoCl}_{2}$ treatment, and (d) cyclin B1i cells after $\mathrm{CoCl}_{2}$ treatment. (i-1) ICC staining of Chk1. (a) control cells, (b) cyclin B1i cells, (c) control cells after $\mathrm{CoCl}_{2}$ treatment, and (d) cyclin B1i cells after $\mathrm{CoCl}_{2}$ treatment. (m-p) ICC staining of Chk2. (a) control cells, (b) cyclin B1i cells, (c) control cells after $\mathrm{CoCl}_{2}$ treatment, and (d) cyclin B1i cells after $\mathrm{CoCl}_{2}$ treatment 
A

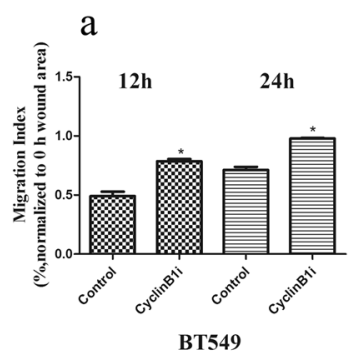

B

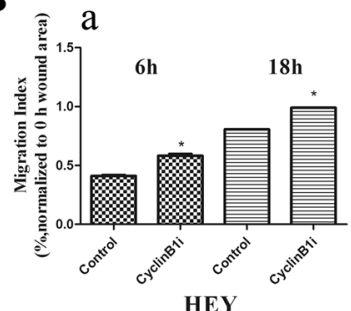

HEY

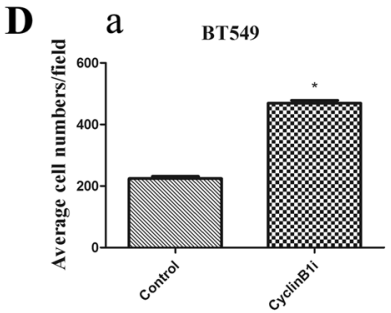

$\mathbf{E}$

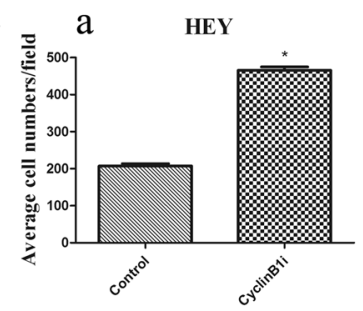

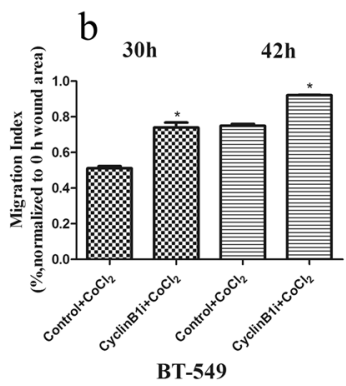

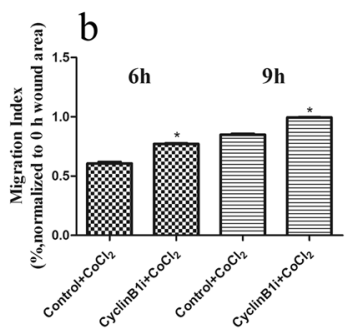

HEY
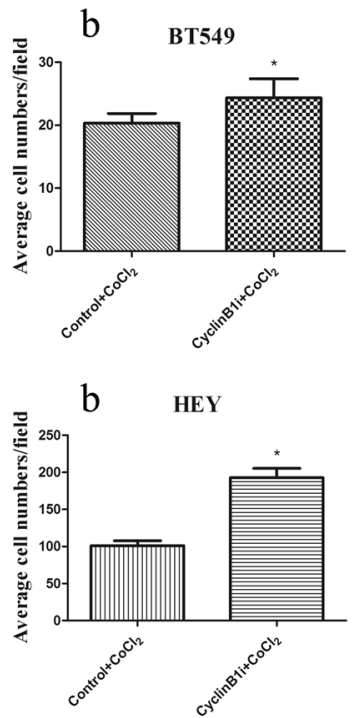

Fig. 4 A (a) Bar graph depicting the differences in the calculated wound healing indices based on measurements of at least 3 different wound areas in control cells and cyclinB1-knockdown BT-549 cells. (b) Bar graph depicting differences in the calculated wound healing indices based on measurements of at least 3 different wound areas between PGCCs and cyclinB1-knockdown PGCCs of BT-549 cells. B (a) Bar graph depicting differences in calculated wound healing indices based on measurements of at least 3 different wound areas in control cells and cyclinB1knockdown cells using HEY cells. (b) Bar graph depicting differences in calculated wound-healing indices based on measurements of at least 3 different wound areas in PGCCs and cyclinB1-knockdown PGCCs using HEY cells. C (a-d) Representative images showing results from the transwell migration assay in control cells, cyclin B1i cells, and PGCCs with budding daughter cells of BT-549 cells $(4 \times)$. (e-h) Representative images showing the results of migration assay in control cells, cyclinB1knockdown cells, and PGCCs with budding daughter cells using HEY cells $(4 \times)$. D (a) Results of transwell invasion assay in control cells and cyclin B1i cells using BT-549 cells. (b) Results of transwell invasion assay in PGCCs and cyclin B1i PGCCs in BT-549 cells. e. (a) Results of
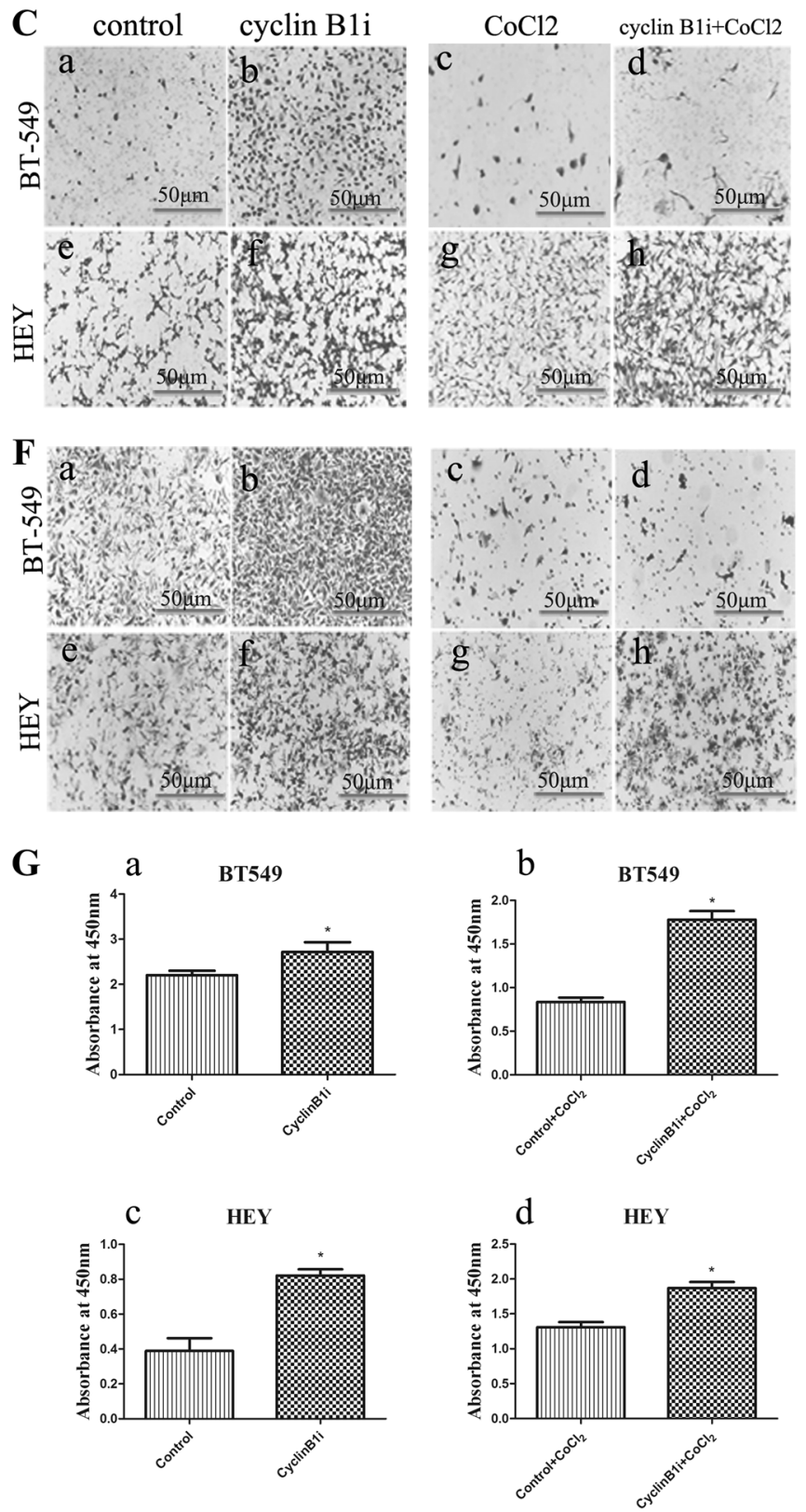

transwell invasion assay for control cells and cyclin B1i cells using HEY cells. (b) Results of invasion assay for PGCCs and cyclin B1i PGCCs using HEY cells. F (a-d) Representative images showing the results of invasion assay in control cells, cyclin B1i cells, and PGCCs with budding daughter cells in BT-549 cells (4×). (e-h) Representative images showing the results of invasion assay in control cells, cyclin B1i cells, and PGCCs with budding daughter cells using HEY cells $(4 \times)$. G (a) Bar graph depicts differences in cell proliferation ability between control cells and cyclin B1i cells using BT-549 cells based on CCK-8 assay. All data are expressed as mean $\pm \mathrm{SD}$ of 3 independent experiments. (b) Bar graph depicting differences in cell proliferation ability between PGCCs and cyclin B1i PGCCs using BT-549 cells based on CCK-8 assay. All data are expressed as mean \pm SD of 3 independent experiments. (c) Bar graph depicting differences in cell proliferation abilities between control and cyclin B1i cells using HEY cells based on CCK-8 assay. All the data are expressed as mean \pm SD of 3 independent experiments. (d) Bar graph depicting differences in cell proliferation abilities between PGCCs and cyclin B1i PGCCs using HEY cells based on CCK-8 assay. All data are expressed as mean $\pm \mathrm{SD}$ of 3 independent experiments 
transwell inserts. The numbers of invasive cells were markedly higher in cyclin B1i cells and cyclin B1i PGCCs compared to those of control cells and PGCCs. Quantitative results of transwell invasion assays showed significant differences in the numbers of invasive cells for both BT-549 (Supplementary Table 5; $t=-48.383, P=0.000$ for cyclin B1i and $t=-2.028, P=0.112$ for $\mathrm{CoCl}_{2}$ ) and HEY cells (Supplementary Table 6; $t=-51.271, P=0.000$ for cyclin B1i and $t=-14.433, P=0.000$ for $\mathrm{CoCl}_{2}$ ) (Fig. 4D-F). Only PGCCs and cyclin B1i PGCCs showed no significant differences in the numbers of invasive cells. Furthermore, we examined the proliferation abilities of control cells and cyclin B1i cells before and after $\mathrm{CoCl}_{2}$ treatment. Results of the CCK-8 assay showed that cells subjected to cyclin B1i and $\mathrm{CoCl}_{2}$ treatment exhibited faster growth compared to control cells for both BT-549 (Supplementary Table 7; $t=$ $-3.703, P=0.021$ for cyclin B1i and $t=-14.710, P=$ 0.000 for $\mathrm{CoCl}_{2}$ ) and HEY cells (Supplementary Table 8; $t$ $=-9.127, P=0.001$ for cyclin B1i and $t=-8.386, P=$ 0.001 for $\mathrm{CoCl}_{2}$ ) (Supplementary Table 8, Fig. 4G).

\section{Cyclin B1 IHC staining in animal tumors formed from injected PGCCs or parental control cells}

The parental control BT-549 and HEY cells and their respective PGCCs, were used to form tumors in recipient animals. One month later, tumor nodules with an average size of $1.0 \mathrm{~cm}$ formed in animals injected with the BT-549 and HEY parental control cells, and in animals injected with respective PGCCs. The tumors were removed and fixed in $10 \%$ formalin for H\&E and cyclin B1 IHC staining. The $\mathrm{H} \& \mathrm{E}$ staining shows that there were more giant tumor cells in the animals subjected to the PGCCs injections than from those subjected to control cell injections. The tumor cells resulting from PGCCs injection had a higher nucleus:cytoplasm ratio and a higher proportion of cells with spindle cell morphology compared to the tumor cells formed from control cell injections (Fig. 5A a, b). IHC staining confirmed that there was a higher number of cyclin B1-positive cells in tumor tissue from animals subjected to PGCC injections than from those subjected to control cell injections (Table 3), and cyclin B1 was located in the cytoplasm of the giant tumor cells from PGCC-injected animals (Fig. 5A d, f). Furthermore, in tumor tissue from control cell-injected animals, positive cyclin B1 staining was found in the nuclei of the tumor cells (Fig. 5A c, e).

\section{Number of PGCCs and breast and ovarian cancer grade}

Using the definition of PGCCs as described by Zhang et al., PGCCs with giant or multiple nuclei were clearly observed in breast cancers and ovarian cancers with different grades (Figs. 5B and 6A). As shown in Table 4, the average number of PGCCs in the metastatic breast cancer (group 1) was higher than that of primary breast cancer (group 2) (Fig. 5C a). This difference was statistically significant $(P$ $=0.000$ ). In ovarian serous cancers, lymph node metastatic ovarian cancers (group II) had the most PGCCs, and serous borderline cystadenoma (group IV) had the least PGCCs (Fig. 6B). The differences among these 4 groups of ovarian serous tumor were statistically significant $(P=0.000)$ (Table 4).

\section{Expression and subcellular localization of cyclin B1 and CDC25 in human breast and ovarian serous cancer}

Since the number of PGCCs appeared to be related to tumor grade in both breast cancer and ovarian serous cancer, we examined the relation of the formation of PGCCs and the expression and subcellular location of cyclin B1, CDC25B, and CDC25C. To examine this relation, we performed IHC staining on 188 samples of formalin-fixed, paraffinembedded human breast cancer tissues and 67 samples of human ovarian cancer tissues. In agreement with the ICC staining data, positive staining for cyclin B1 appeared mainly in the cytoplasm of the PGCCs and in the nuclei of diploid cancer cells (Figs. 5B and 6A). The differences in the cyclin B1 staining indexes between human breast cancer group 1 and group 2 were statistically significant $(P=0.009)$ (Table 5). Compared to the primary breast cancer (group 2), there were more cells with positive cytoplasmic cyclin staining in metastatic breast cancer. In ovarian serous tumors, the staining index was highest in lymph node metastatic ovarian cancer (Table 5). Positive staining for both CDC25B (Figs. 5B and 6A) and $\mathrm{CDC} 25 \mathrm{C}$ was detected in both the nuclei and cytoplasm (Figs. 5B and 6A); the differences in positive cytoplasmic staining rate for $\mathrm{CDC} 25 \mathrm{~B}$ and $\mathrm{CDC} 25$ $\mathrm{C}$ among the different human breast cancer and ovarian serous cancer groups were significant $(P=0.004$ for breast cancer, $P=0.000$ for ovarian serous cancer), as shown in Table 6. For breast cancer, the average positive cytoplasmic staining for $\mathrm{CDC} 25 \mathrm{~B}$ and $\mathrm{CDC} 25 \mathrm{C}$ in metastatic breast cancer was more than that in primary breast cancer (Fig. 5C b, c). Similar results for human ovarian cancer are shown in Fig. $6 \mathrm{D}$, E. The average number of cells showing positive cytoplasmic staining for CDC25B and CDC25C in group II was higher than those in group I and group III, verifying that the number of cells showing positive cytoplasmic staining for $\mathrm{CDC} 25 \mathrm{~B}$ and $\mathrm{CDC} 25 \mathrm{C}$ increased with tumor grade and lymph node metastasis.

\section{Discussion}

One of the most prominent features of cancer cells is uncontrolled proliferation, which is mostly attributed to 

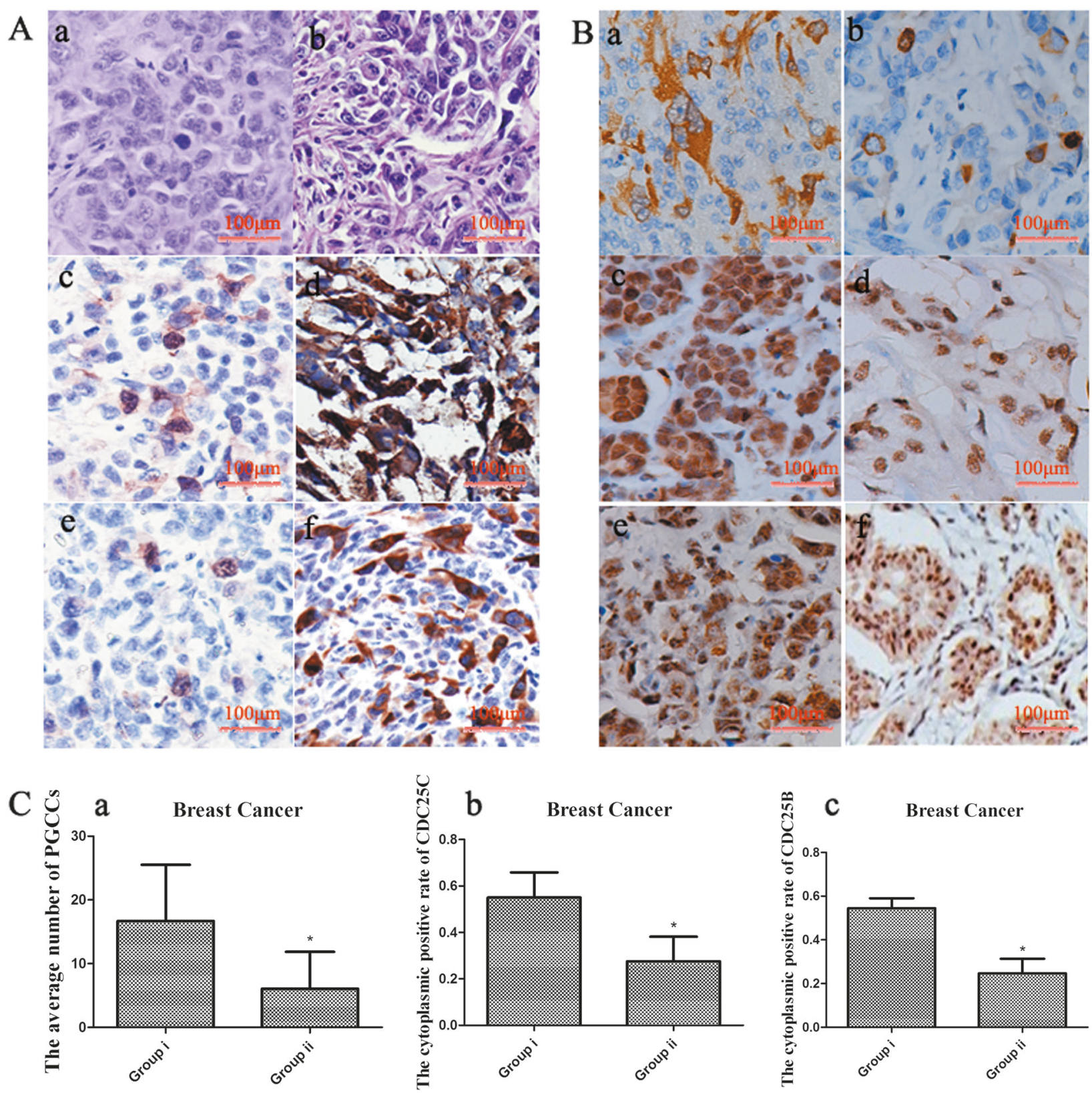

Fig. 5 A Animal xenografts of BT-549 and HEY cells. (a) Morphologic characteristics of animal xenografts following injection of HEY parental control cells $(H \& E, 10 \times)$. (b) Morphologic characteristics of animal xenografts from injection of HEY PGCCs (H\&E, 10×). (c) Cyclin B1 IHC staining of animal xenografts from injection of BT-549 parental control cells $(\mathrm{IHC}, 10 \times)$. (d) Cyclin B1 IHC staining of animal xenografts from injection of BT-549 PGCCs (IHC, 10×). (e) Cyclin B1 IHC staining of animal xenografts from the injection of HEY control cells (IHC, 10× ). (f) Cyclin B1 IHC staining of animal xenografts from injection of HEY PGCCs (IHC, 10×). B Cyclin B1

dysregulation of the cell cycle. Hence, it is often the dysregulation of cell-cycle-related proteins that endows cancer cells with the ability to invade, metastasize, develop chemoresistance, and become resistant to apoptosis [12]. Among the cell-cycle-related proteins, cyclin B1 and expression in (a) lymph node metastatic breast cancer, (b) primary breast cancer; CDC25B expression in (c) lymph node metastatic breast cancer, and (d) primary breast cancer; CDC25C expression in (e) lymph node metastatic breast cancer, and (f) primary breast cancer. $\mathbf{C}$ (a) Bar graph showing the average number of PGCCs in lymph node metastatic breast cancer (Gp1) and primary breast cancer (Gp2). b) Bar graph showing the cytoplasmic positive rate of CDC25B in metastatic breast cancer and primary breast cancer. c) Bar graph showing the cytoplasmic positive rate of $\mathrm{CDC} 25 \mathrm{C}$ in metastatic breast cancer and primary breast cancer

CDC25 play important roles in regulating progression through the cell cycle, and they are involved in the development of a variety of human malignancies. To be more precise, cyclin B1 is a key cyclin involved in the $\mathrm{G} 2 / \mathrm{M}$ phase transition of the cell cycle, and it is overexpressed in 
Table 3 Average number of cyclin B1-positive cells per high-power field filled with mostly tumor cells in animal xenografts from BT-549 and HEY cells

\begin{tabular}{|c|c|c|c|c|c|c|}
\hline & BT-549 & & & HEY & & \\
\hline & $\begin{array}{l}\text { Average number of cyclin B1- } \\
\text { positive cells per high-power } \\
\text { field }\end{array}$ & $t$ & $P$ & $\begin{array}{l}\text { Average number of cyclin B1- } \\
\text { positive cells per high-power } \\
\text { field }\end{array}$ & $t$ & $P$ \\
\hline Control & $37.00 \pm 13.472$ & -9.573 & 0.000 & $17.60 \pm 5.079$ & -12.428 & 0.000 \\
\hline PGCCs & $158.60 \pm 25.006$ & & & $105.00 \pm 14.883$ & & \\
\hline
\end{tabular}

\section{A}

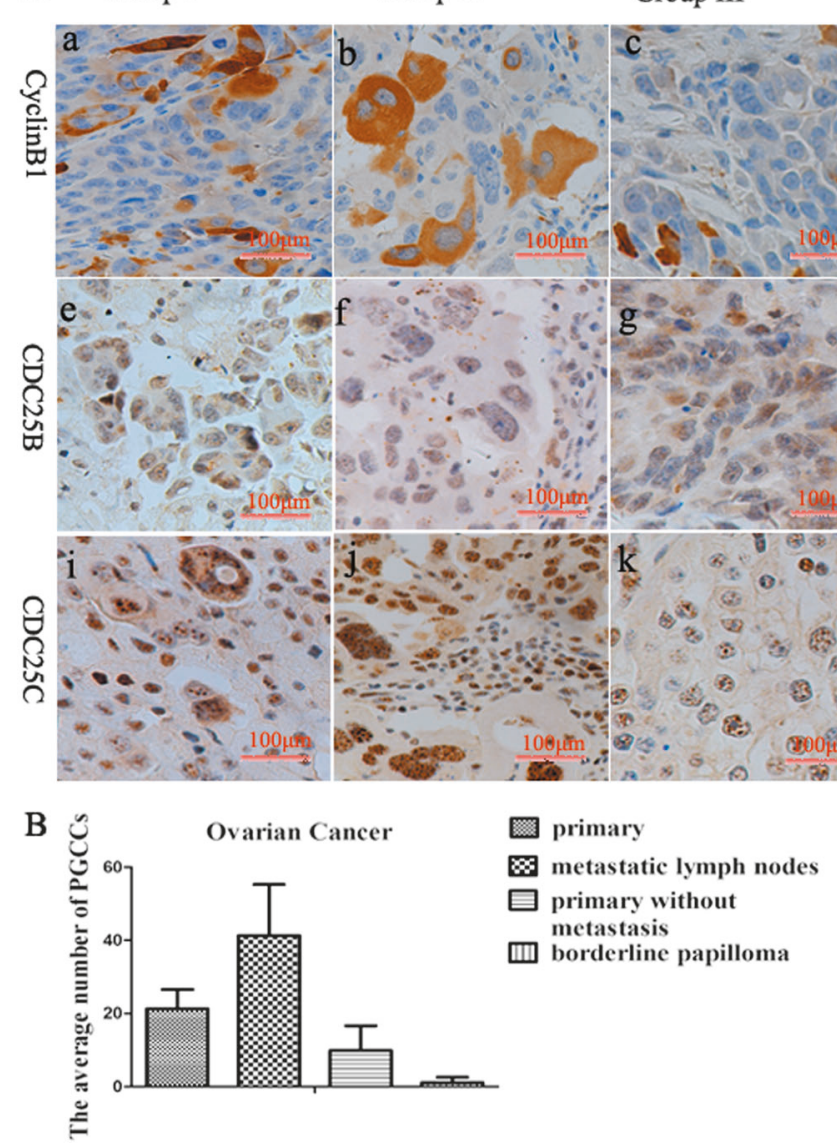

Fig. 6 IHC staining of cyclin B1, CDC25B, and CDC25C in human ovarian tumors. A (a-d). Cyclin B1 expression in (a) primary ovarian serous cancer with lymph node metastasis, (b) lymph node metastatic cancer of (a), (c) primary ovarian cancer without metastasis, and (d) serous borderline cystadenoma (IHC, 10 $\times$ ). (e-h) CDC25B expression in (e) primary ovarian serous cancer with lymph node metastasis, (f) lymph node metastatic cancer of (e), (g) primary ovarian cancer without metastasis, and (h) serous borderline cystadenoma (IHC, 10x). (i-1) CDC25C expression in (i) primary ovarian serous cancer with lymph node metastasis, (j) lymph node metastatic cancer of (i), (k)

various malignant tumors. CDC25 is also a key regulator of several steps in the cell cycle, acting by dephosphorylating and activating cyclin-dependent kinases (CDKs) [26-28]. There are 3 different human isoforms of CDC25: CDC25A, which mainly acts at G1/S transition, and CDC25B and CDC25C, which play roles in G2/M transition $[29,30]$. The different roles played by these CDC25 isoforms in the cell cycle are associated with their intracellular localization;
Group IV

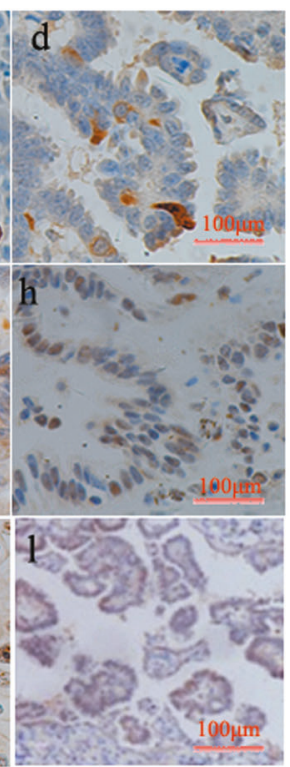

E

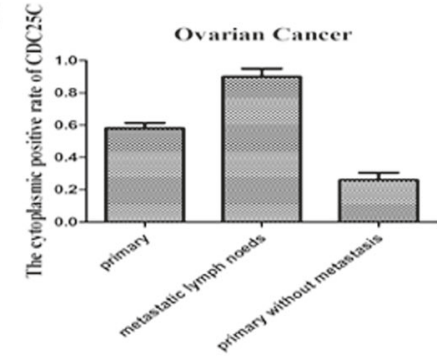

primary ovarian cancer without metastasis, and (1) serous borderline cystadenoma (IHC, 10×). B Bar graph showing the average number of PGCCs in human ovarian tumors of different grades (Group 1-4). C Bar graph showing the differences in staining index for cyclin B1 in human ovarian tumors with different grades (Group 1 to group 4). D Bar graph showing the differences in staining index for CDC25B in human ovarian tumors with different grades (Group 1 to 4). E Bar graph showing the differences in staining index for CDC25C in human ovarian tumors with different grades (Group 1-4)

CDC25A is a nuclear protein, whereas $\mathrm{CDC} 25 \mathrm{~B}$ and CDC25C shuttle in and out the nucleus throughout the cell cycle [31-33]. Overexpression of CDC25C leads to the hyperactivation of several cyclin B1-CDK1 complexes, resulting in disruption of cell cycle checkpoints and untimely cell-cycle progression, ultimately leading to genomic instability and cancer development. For the same reason, dysregulation of $\mathrm{CDC} 25$, along with a lack of cyclin 
B1-CDK1 complex activity, may lead to the generation of a rate-limiting stimulus for $\mathrm{G} 2 / \mathrm{M}$ transition, thus delaying completion of the cell cycle [34, 35].

Recent studies have confirmed that the cell cycle plays an important role in balanced replication and distribution of genetic material to daughter cells. A polyploid genome and increase in cell size lead to the generation of PGCCs. These phenomena result from an abnormal cell cycle, including continued DNA replication and aberrant cell division [13-15, 17-19]. PGCCs are thought to originate from the failure of mitosis, and be the products of genomic instability [36, 37]. PGCCs vary in number in different pathologic grades of cancer. In this study, PGCCs could be generated in vitro by using $\mathrm{CoCl}_{2}$ to induce hypoxia and mitotic failure in BT-549 and HEY cells. Previous studies have reported that hypoxia is associated with alterations in G2/M checkpoint regulators, including cyclin $\mathrm{B} 1$ and $\mathrm{CDC} 25$, and

Table 4 Comparison of the average number of PGCCs in human breast cancer and ovarian cancer

\begin{tabular}{llllll}
\hline & Tumor & $n$ & $\begin{array}{l}\text { Number of } \\
\text { PGCCs }\end{array}$ & $\begin{array}{l}\text { Value of } \\
\text { statistic }\end{array}$ & $P$ value \\
\hline Breast & Group 1 & 54 & $16.68 \pm 8.83$ & $Z=$ & 0.000 \\
Cancer & Group 2 & 134 & $6.05 \pm 5.81$ & -18.103 & \\
Ovarian & Group I & 15 & $21.27 \pm 5.30$ & $\chi^{2}=$ & 0.000 \\
Cancer & Group II & 15 & $41.31 \pm$ & 244.221 & \\
& & & 13.96 & & \\
& Group III & 29 & $9.88 \pm 6.74$ & & \\
& Group IV & 8 & $1.10 \pm 1.46$ & & \\
\hline
\end{tabular}

Table 5 Differences of cyclin B1 expression in human breast cancer and ovarian cancer

\begin{tabular}{llllll}
\hline Tumor & Group & $\mathrm{n}$ & $\begin{array}{l}\text { Staining index } \\
\text { for cyclin B1 }\end{array}$ & $\begin{array}{l}\text { Value of } \\
\text { statistic }\end{array}$ & $P$ \\
\hline Breast & Group 1 & 54 & $1.15 \pm 1.25$ & $Z=$ & 0.009 \\
cancer & Group 2 & 134 & $0.66 \pm 0.96$ & -2.616 & \\
Ovarian & Group I & 15 & $1.87 \pm 1.68$ & $\chi^{2}=$ & 0.000 \\
cancer & Group II & 15 & $3.13 \pm 2.42$ & 15.540 & \\
& Group III & 29 & $0.93 \pm 0.96$ & & \\
& Group IV & 8 & $0.05 \pm 0.00$ & & \\
\hline
\end{tabular}

there is increased $\mathrm{G} 2 / \mathrm{M}$ arrest in PGCCs after $\mathrm{CoCl}_{2}$ treatment $[16,38]$. Consequently, G2/M arrest induced by hypoxia is associated with the expression and subcellular localization of cell-cycle-related proteins [4, 6, 38].

As discussed earlier, cyclin B1-CDK1 is involved in the early events of mitosis. Before mitosis, almost all cyclin B1 in the cell is located in the cytoplasm, but in late prophase the cyclin B1-CDK1 complex translocates to the nucleus, triggering the nuclear events of mitosis [39]. The activation and relocation to the nucleus of cyclin B1-CDK1 complexes is catalyzed by the dual-specificity $\mathrm{CDC} 25$ phosphatases [40]. Although there are two forms of cyclin B proteins in mammalian cells, cyclin B1 is thought to be responsible for most of the actions of CDKs, whereas cyclin B2 is considered to be a non-essential protein [41, 42]. On the basis of these observations, the expression level and intracellular localization of cyclin B1 and CDC25 were the major targets of this study. During interphase, cyclin B1-CDK complexes are found entirely in the cytoplasm, where they are held in an inactive state due to CDK phosphorylation. CDK is activated at the onset of mitosis by CDC25 phosphatases, which dephosphorylate CDK. In late prophase, most of the cyclin B1-CDK complexes translocate rapidly from the cytoplasm to the nucleus [39, 43]. Thus, the dephosphorylation of CDK and the translocation of cyclin B1CDK complexes into the nucleus play an important role in governing the onset of nuclear mitotic events. Here, our data show that the average positive staining of cyclin B1 was clearly decreased in cells after $\mathrm{CoCl}_{2}$ treatment, and positive cyclin $\mathrm{B} 1$ staining was mainly observed in the cytoplasm of PGCCs, suggesting that cyclin B1-CDK complexes failed to translocate into the nucleus. Hence, these two key processes (decreased expression and increased cytoplasmic localization) together participate in delaying G2/M transition and blocking entry into mitosis. This likely explains the formation of multiple and giant nuclei in PGCCs.

During prophase, activated cyclin B1-CDK complexes mutually activate both $\mathrm{CDC} 25 \mathrm{~B}$ and $\mathrm{CDC} 25 \mathrm{C}$ in a feedforward loop, resulting in mitotic entry [32, 33, 44]. In this study, we observed an increase in positive cytoplasmic staining for $\mathrm{CDC} 25 \mathrm{~B}$ and $\mathrm{CDC} 25 \mathrm{C}$ in metastatic cancer.
Table 6 Average rate of human breast cancer and ovarian tumors positive for cytoplasmic CDC25B and CDC25C

\begin{tabular}{lllllllll}
\hline Tumor & Group & $n$ & $\begin{array}{l}\text { Rate of cells } \\
\text { positive for } \\
\text { cytoplasmic } \\
\text { CDC25B }\end{array}$ & $\begin{array}{l}\text { Value of } \\
\text { statistic }\end{array}$ & $\begin{array}{l}P \text { value } \\
\text { Rate of cells } \\
\text { positive for } \\
\text { cytoplasmic } \\
\text { CDC25C }\end{array}$ & $\begin{array}{l}\text { Value of } \\
\text { statistic }\end{array}$ & $P$ value \\
\hline $\begin{array}{l}\text { Breast } \\
\text { cancer }\end{array}$ & Group 1 & 54 & $0.5447 \pm 0.0459$ & $t=8.249$ & 0.000 & $0.5501 \pm 0.1079$ & $t=4.056$ & 0.004 \\
Ovarian & Group 2 & 134 & $0.2471 \pm 0.0664$ & & & $0.2757 \pm 0.1060$ & & \\
cancer & Group I & 15 & $0.5142 \pm 0.0366$ & $F=$ & 0.000 & $0.5808 \pm 0.0332$ & $F=$ & 0.000 \\
& Group II & 15 & $0.8349 \pm 0.0528$ & 130.777 & & $0.8803 \pm 0.0392$ & 315.518 & \\
& Group III & 29 & $0.3060 \pm 0.0634$ & & & $0.2615 \pm 0.0438$ & & \\
\hline
\end{tabular}


We hypothesize that the failure of nuclear translocation and the downregulation of cyclin B1, CDC25B, and CDC25C cause checkpoint defects and mitotic abnormalities, which may underlie the formation of PGCCs. However, we know little about the mechanism underlying the failure of the nuclear translocation process. There are two other important kinases that positively regulate cyclin B1 and CDC25 and promote mitosis: Aurora-A kinase and the polo-like kinase 1 (PLK1) [45-48]. The former activates CDC25, whereas the latter favors the nuclear import of cyclin B1, CDC25B, and $\mathrm{CDC} 25 \mathrm{C}$. Aurora-A kinase activates $\mathrm{CDC} 25 \mathrm{~B}$ and CDC25C by phosphorylating cyclin B1-CDK1 complexes [29, 49, 50]. Aurora-A kinase phosphorylates CDC25, leading to entry into mitosis. PLK1 is a key regulator essential for the translocation of cyclin B1, CDC25B, and $\mathrm{CDC} 25 \mathrm{C}$ from the cytoplasm to the nucleus, and for regulation of G2/M transition. Our data show that the expression level of Aurora-A decreased in PGCCs after $\mathrm{CoCl}_{2}$ treatment, which led to the failure of cyclin $\mathrm{B} 1$ and $\mathrm{CDC} 25$ nuclear translocation. Furthermore, there are many other kinases and phosphatases that regulate the activity and nuclear translocation of cyclin B1, CDC25B, and CDC25C, including protein kinase A (PKA) and checkpoint kinases (Chk1 and Chk2) [51-54]. Western blotting confirmed that the expression level of Chk2 increased after $\mathrm{CoCl}_{2}$ treatment in both BT-549 and HEY cells.

Interestingly, both ICC staining and IHC staining showed that some PGCCs were positive for cyclin B1, whereas other PGCCs were negative. As described above, PGCCs have the properties of cancer stem cells. Liu et al. have reported that there are two kinds of breast cancer stem cells, as characterized by expression of distinct cancer stem cell markers. Mesenchymal-like breast cancer stem cells are characterized as being primarily quiescent, whereas epithelial-like breast cancer stem cells are proliferative [55]. We speculate that there are two kinds of PGCCs with different cell-cycle-related protein expression and subcellular localization. One is proliferative, expressing cell-cyclerelated proteins and generating daughter cells, whereas the other is quiescent. In addition, higher number of PGCCs are detected in poorly differentiated tumors with lymph node metastasis compared to well-differentiated tumors without lymph node metastasis. High levels of expression of cyclin B1 in the cytoplasm and high expression of CDC25B and $\mathrm{CDC} 25 \mathrm{C}$ in the nucleus are associated with high-grade tumors and lymph node metastasis. Therefore, cyclin B1 and CDC25 may be significant in the carcinogenesis of tumors, and they may be potential targets for cancer therapy. Furthermore, we compared the migration, invasion, and proliferation abilities of control cells, cyclin B1i cells, and their PGCCs following $\mathrm{CoCl}_{2}$ treatment. PGCCs treated with $\mathrm{CoCl}_{2}$ exhibited cancer stem cell properties and showed significantly reduced adherent growth. We compared the cell properties between control and cyclin B1i cells and between PGCCs and cyclin B1i PGCCs via wound healing assay, transwell migration and invasion assay, and CCK-8 assay. Results confirmed that inhibition of cyclinB1 and $\mathrm{CoCl}_{2}$ treatment significantly promoted cell proliferation, invasion, and migration abilities.

The results of this study suggest that PGCCs induced by $\mathrm{CoCl}_{2}$ express cyclin $\mathrm{B} 1$ in the cytoplasm. The translocation failure of cyclin $\mathrm{B} 1, \mathrm{CDC} 25 \mathrm{~B}$, and $\mathrm{CDC} 25 \mathrm{C}$ from the cytoplasm into nucleus may be related to the $\mathrm{G} 2 / \mathrm{M}$ arrest seen in PGCCs. A high level of cyclin B1 expression in the cytoplasm is associated with tumor grade and lymph node metastasis in both human ovarian cancer and breast cancer. Furthermore, the expression levels of cell-cycle-related proteins and the regulatory kinases after $\mathrm{CoCl}_{2}$ treatment between HEY and BT-549 cells were not always consistent, which may be related to the wild type p53 in HEY cells and mutant p53 in BT-549 cells. Further studies on the molecular mechanisms of the nuclear translocation failure of cyclin B1 may shed light on the formation of PGCCs and may offer new therapeutic strategies for treating tumors with lymph node metastases.

Acknowledgements This work was partially supported by grants from the National Science Foundation of China (81472729, 81672426), and the foundation of committee on science and technology of Tianjin (17YFZCSY00700 and 17ZXMFSY00120).

\section{Compliance with ethical standards}

Conflict of interest The authors declare that they have no conflict of interest.

\section{References}

1. Dong XL, Xu PF, Miao C, et al. Hypoxia decreased chemosensitivity of breast cancer cell line MCF-7 to paclitaxel through cyclin B1. Biomed Pharmacother. 2012;66:70-5.

2. Lv H, Shi Y, Zhang L, et al. Polyploid giant cancer cells with budding and the expression of cyclin E, S-phase kinase-associated protein 2, stathmin associated with the grading and metastasis in serous ovarian tumor. BMC Cancer. 2014;14:576.

3. Khan N, Mukhtar H. Cancer and metastasis: prevention and treatment by green tea. Cancer Metastas- Rev. 2010;29:435-45.

4. Fei F, Zhang D, Yang Z, et al. The number of polyploid giant cancer cells and epithelial-mesenchymal transition-related proteins are associated with invasion and metastasis in human breast cancer. J Exp Clin Cancer Res. 2015;34:158.

5. Zhang D, Yang X, Yang Z, et al. Daughter cells and erythroid cells budding from PGCCs and their clinicopathological significances in colorectal cancer. J Cancer. 2017;8:469-78.

6. Zhang S, Mercado-Uribe I, Hanash S, et al. iTRAQ-based proteomic analysis of polyploid giant cancer cells and budding progeny cells reveals several distinct pathways for ovarian cancer development. PLoS ONE. 2013;8:e80120.

7. Zhang S, Mercado-Uribe I, Liu J. Tumor stroma and differentiated cancer cells can be originated directly from polyploid giant cancer cells induced by paclitaxel. Int J Cancer. 2014;134:508-18. 
8. Zhang D, Wang Y, Zhang S. Asymmetric cell division in polyploid giant cancer cells and low eukaryotic cells. Biomed Res Int. 2014;2014:432652.

9. Hagting A, Jackman M, Simpson K, et al. Translocation of cyclin B1 to the nucleus at prophase requires a phosphorylationdependent nuclear import signal. Curr Biol. 1999;9:680-9.

10. Mullers E, Silva Cascales H, Jaiswal H, et al. Nuclear translocation of Cyclin B1 marks the restriction point for terminal cell cycle exit in G2 phase. Cell Cycle. 2014;13:2733-43.

11. Suzuki T, Urano T, Miki Y, et al. Nuclear cyclin B1 in human breast carcinoma as a potent prognostic factor. Cancer Sci. 2007;98:644-51.

12. Shen T, Huang $\mathrm{S}$. The role of Cdc25A in the regulation of cell proliferation and apoptosis. Anticancer Agents Med Chem. 2012;12:631-9.

13. Fox DT, Duronio RJ. Endoreplication and polyploidy: insights into development and disease. Development. 2013;140:3-12.

14. Niu N, Zhang J, Zhang N, et al. Linking genomic reorganization to tumor initiation via the giant cell cycle. Oncogenesis. 2016;5: e281.

15. Duncan AW, Taylor MH, Hickey RD, et al. The ploidy conveyor of mature hepatocytes as a source of genetic variation. Nature. 2010;467:707-10.

16. Hasvold G, Lund-Andersen C, Lando M, et al. Hypoxia-induced alterations of G2 checkpoint regulators. Mol Oncol. 2016;10:764-73.

17. McCluggage WG, Lyness RW, Atkinson RJ, et al. Morphological effects of chemotherapy on ovarian carcinoma. J Clin Pathol. 2002;55:27-31.

18. Orr-Weaver TL. When bigger is better: the role of polyploidy in organogenesis. Trends Genet. 2015;31:307-15.

19. Vitale I, Galluzzi L, Senovilla L, et al. Illicit survival of cancer cells during polyploidization and depolyploidization. Cell Death Differ. 2011;18:1403-13.

20. Jia L, Zhang S, Ye Y, et al. Paclitaxel inhibits ovarian tumor growth by inducing epithelial cancer cells to benign fibroblast-like cells. Cancer Lett. 2012;326:176-82.

21. Huang H, Chen Z, Ni X. Tissue transglutaminase-1 promotes stemness and chemoresistance in gastric cancer cells by regulating Wnt/beta-catenin signaling. Exp Biol Med. 2017;242:194-202.

22. Wang $\mathrm{Y}, \mathrm{Gu} \mathrm{YH}$, Liu M, et al. Fluoxetine protects against methamphetamineinduced lung inflammation by suppressing oxidative stress through the SERT/p38 MAPK/Nrf2 pathway in rats. Mol Med Rep. 2017;15:673-80.

23. Zhang S, Zhang D, Zhu Y, et al. Clusterin expression and univariate analysis of overall survival in human breast cancer. Technol Cancer Res Treat. 2006;5:573-8.

24. Zhang L, Ding P, Lv H, et al. Number of polyploid giant cancer cells and expression of EZH2 are associated with VM formation and tumor grade in human ovarian tumor. Biomed Res Int. 2014;2014:903542.

25. Sun B, Zhang S, Zhang D, et al. Identification of metastasisrelated proteins and their clinical relevance to triple-negative human breast cancer. Clin Cancer Res. 2008;14:7050-9.

26. Ye C, Wang J, Wu P, et al. Prognostic role of cyclin B1 in solid tumors: a meta-analysis. Oncotarget. 2017;8:2224-32.

27. Sur S, Agrawal DK. Phosphatases and kinases regulating CDC 25 activity in the cell cycle: clinical implications of CDC25 overexpression and potential treatment strategies. Mol Cell Biochem. 2016;416:33-46.

28. Brenner AK, Reikvam H, Lavecchia A, et al. Therapeutic targeting the cell division cycle 25 (CDC25) phosphatases in human acute myeloid leukemia--the possibility to target several kinases through inhibition of the various CDC25 isoforms. Molecules. 2014;19:18414-47.
29. Boutros R, Lobjois V, Ducommun B. CDC25 phosphatases in cancer cells: key players? Good targets? Nat Rev Cancer. 2007;7:495-507.

30. Aressy B, Ducommun B. Cell cycle control by the CDC 25 phosphatases. Anticancer Agents Med Chem. 2008;8:818-24.

31. Hoffmann I, Draetta G, Karsenti E. Activation of the phosphatase activity of human cdc25A by a cdk2-cyclin $\mathrm{E}$ dependent phosphorylation at the G1/S transition. EMBO J. 1994;13:4302-10.

32. Ferguson AM, White LS, Donovan PJ, et al. Normal cell cycle and checkpoint responses in mice and cells lacking Cdc25B and Cdc25C protein phosphatases. Mol Cell Biol. 2005;25:2853-60.

33. Chen MS, Hurov J, White LS, et al. Absence of apparent phenotype in mice lacking Cdc25C protein phosphatase. Mol Cell Biol. 2001;21:3853-61.

34. Ray D, Kiyokawa H. CDC25A phosphatase: a rate-limiting oncogene that determines genomic stability. Cancer Res. 2008;68:1251-3.

35. Mailand N, Podtelejnikov AV, Groth A, et al. Regulation of G(2)/ $\mathrm{M}$ events by Cdc25A through phosphorylation-dependent modulation of its stability. EMBO J. 2002;21:5911-20.

36. Geigl JB, Obenauf Ac, Schwarzbraun T, et al. Defining 'chromosomal instability'. Trends Genet. 2008;24:64-9.

37. Holland AJ, Cleveland DW. Boveri revisited: chromosomal instability, aneuploidy and tumorigenesis. Nat Rev Mol Cell Biol. 2009;10:478-87.

38. Zhang S, Mercado-Uribe I, Xing Z, et al. Generation of cancer stem-like cells through the formation of polyploid giant cancer cells. Oncogene. 2014;33:134.

39. Takizawa CG, Morgan DO. Control of mitosis by changes in the subcellular location of cyclin-B1-Cdk1 and Cdc25C. Curr Opin Cell Biol. 2000;12:658-65.

40. Timofeev O, Cizmecioglu O, Settele F, et al. Cdc25 phosphatases are required for timely assembly of CDK1-cyclin B at the G2/M transition. J Biol Chem. 2010;285:16978-90.

41. Jackman M, Firth M, Pines J. Human cyclins B1 and B2 are localized to strikingly different structures: B1 to microtubules, B2 primarily to the Golgi apparatus. EMBO J. 1995;14:1646-54.

42. Brandeis M, Rosewell I, Carrington M, et al. Cyclin B2-null mice develop normally and are fertile whereas cyclin B1-null mice die in utero. Proc Natl Acad Sci USA. 1998;95:4344-9.

43. Wang Z, Trope CG, Florenes VA, et al. Overexpression of CDC25B, CDC25C and phospho-CDC25C (Ser216) in vulvar squamous cell carcinomas are associated with malignant features and aggressive cancer phenotypes. BMC Cancer. 2010;10:233.

44. Lincoln AJ, Wickramasinghe D, Stein P, et al. Cdc25b phosphatase is required for resumption of meiosis during oocyte maturation. Nat Genet. 2002;30:446-9.

45. Cazales M, Schmitt E, Montembault E, et al. CDC25B phosphorylation by Aurora-A occurs at the G2/M transition and is inhibited by DNA damage. Cell Cycle. 2005;4:1233-8.

46. Dutertre S, Cazales M, Quaranta M, et al. Phosphorylation of CDC25B by Aurora-A at the centrosome contributes to the G2-M transition. J Cell Sci. 2004;117:2523-31.

47. Lobjois V, Froment C, Braud E, et al. Study of the dockingdependent PLK1 phosphorylation of the CDC25B phosphatase. Biochem Biophys Res Commun. 2011;410:87-90.

48. Lobjois V, Jullien D, Bouche JP, et al. The polo-like kinase 1 regulates $\mathrm{CDC} 25 \mathrm{~B}-$ dependent mitosis entry. Biochim Biophys Acta. 2009;1793:462-8.

49. Macurek L, Lindqvist A, Medema RH. Aurora-A and hBora join the game of Polo. Cancer Res. 2009;69:4555-8.

50. Seki A, Coppinger JA, Jang CY, et al. Bora and the kinase Aurora a cooperatively activate the kinase Plk1 and control mitotic entry. Science. 2008;320:1655-8. 
51. Loffler H, Rebacz B, Ho AD, et al. Chk1-dependent regulation of Cdc25B functions to coordinate mitotic events. Cell Cycle. 2006;5:2543-7.

52. Pirino G, Wescott MP, Donovan PJ. Protein kinase A regulates resumption of meiosis by phosphorylation of $\mathrm{Cdc} 25 \mathrm{~B}$ in mammalian oocytes. Cell Cycle. 2009;8:665-70.

53. Vazquez-Novelle MD, Mailand N, Ovejero S, et al. Human Cdc14A phosphatase modulates the G2/M transition through Cdc25A and Cdc25B. J Biol Chem. 2010;285:40544-53.
54. Xiao J, Liu C, Hou J, et al. Ser149 is another potential PKA phosphorylation target of Cdc25B in G2/M transition of fertilized mouse eggs. J Biol Chem. 2011;286:10356-66.

55. Liu S, Cong Y, Wang D, et al. Breast cancer stem cells transition between epithelial and mesenchymal states reflective of their normal counterparts. Stem Cell Rep. 2014;2:78-91. 